\title{
THE FORMATION AND SIGNIFICANCE OF POLYCONJUGATED SYSTEMS IN THERMAL AND THERMO-OXIDATIVE PROCESSES
}

\author{
A. A. BERLIN \\ Institute of Physical Chemistry, Academy of Sciences, Moscow, USSR
}

\begin{abstract}
The processes of formation of polyconjugated fragments during thermal oxidation of polymers and the reactions of low molecular compounds yielding polymers with an extended system of conjugation are considered. It is shown from the experimental data that the polyconjugated system (PCS) formed during thermal oxidation and thermolysis exerts initiating or activating action during the process. The cause of such properties of the PCS is the existence in macromolecules of stable biradicals capable of complex formation with diamagnetic molecules. In this complex the radical reactivity is enhanced due to an increased probability of $\mathbf{S}-\mathrm{T}$ transfer (effect of local activation). Initiation of hydroperoxide decomposition caused by the PCS explains the high synergetic action of mixtures of polyconjugated polymers formed during thermal oxidation or thermolysis of monomeric inhibitors (bisphenols, aromatic amines, etc.) and initial monomers not subjected to such treatment. It is shown that during thermolysis along with paramagnetic centres (PMC), the active radicals are formed due to the rupture of valence bonds. These $\sigma$-radicals stabilized by a rigid matrix diminish the thermal-oxidative stability when molecular mobility is 'frozen'. The activity of $\sigma$-radicals, under proper conditions, can suppress the inhibiting effect of stable PMC complexes and cause transition from oxidation to burning. The probability of purposeful regulation of PCS action is associated with the information about the PMC formation mechanism during the growth of polyconjugated chain.

The author's attitude concerning the existence of paramagnetic branched chains resulting from local $\pi$-bonds unpairing in PCS is considered. Due to this fact a paramagnetic avalanche is formed because of $S-T$ transition activation in a complex with other macromolecules by PMC formed during the preceding step. The advanced theory is in excellent agreement with known experimental data and may be useful for interpretation and prediction of the results of future investigations.
\end{abstract}

By means of thermodynamic calculations it is easy to show that in many cases the propagation of a polyconjugated chain is the most probable process in the thermal and thermo-oxidative destruction of organic compounds ${ }^{1}$. The reason for this is connected with the decrease in internal energy for the transition from 'saturated' compounds to substances with a system of 


\section{A. A. BERLIN}

conjugation where $\pi$-electrons have the property of intra intermolecular delocalization $^{2}$. For an appropriate length of effective conjugation, free spins appear in the latter compounds which have a great influence on the physicochemical properties of polyconjugated systems ('the effect of local activation'-ELA) ${ }^{3}$.

In spite of 'thermodynamic advantages' for the transition to polyconjugated systems (PCS) and eventually to graphite, the rate of this process may be low on account of the real kinetic conditions. For example, although the chemical transformation

$$
\sim \mathrm{CF}_{2}-\mathrm{CF}_{2} \sim \rightarrow \mathrm{C}_{\text {graf }}+\mathrm{CF}_{4}
$$

occurs with a large negative $\Delta F(38 \mathrm{kcal} / \mathrm{mol})$ under real conditions, thermolysis and radiolysis of polytetrafluoroethylene lead mainly to the formation of monomer.

Nevertheless, real kinetics cannot exclude absolutely the process which is advantageous from the thermodynamic point of view. Therefore, even in these cases when for given conditions other processes of destruction take place and PCS form with low rate, we cannot neglect their influence. It is especially true because PCS have a high inhibiting and catalytic activity in radical and some other reactions as has been proved in our research ${ }^{3-6}$ and lately in the works of some other authors ${ }^{6.7}$.

In conformity with the problem of stabilization of low molecular and polymer compounds with respect to thermal, photo and radiation effects, the knowledge of the mechanism of PCS formation, their properties and the influence on the substrate transformation under the given conditions, is undoubtedly the main clue to the solution of the scientific and applied problems. It is clear that the development of these ideas is also very important for the directed synthesis of highly thermostable and other polymers.

Thus, it is easy to postulate the importance of the chemistry of polymers with the system of conjugation as the basis of both the synthesis of polymers with specific electrophysical properties and the field of obtaining polymer substances which can be used under the increasingly complicated conditions of modern techniques.

Although the ideas formulated above have been repeatedly expressed and experimentally proved since 1950 , they are not taken into account in those works which neglect progress in the chemistry of polyconjugated systems.

Therefore we shall briefly consider some data illustrating the specificity of the physicochemical properties of PCS.

\section{PARAMAGNETIC PROPERTIES OF POLYCONJUGATED POLYMERS AND THEIR INFLUENCE ON THE PHYSICOCHEMICAL PROPERTIES OF SUBSTANCES FORMING COMPLEXES WITH THEM}

At the present time it is well known that polymers with the $\pi-\pi$ and $p-\pi$ systems of conjugation have rather stable paramagnetic centres (PMC) in condensed phase and in solutions with a narrow EPR singlet and a freeelectron $g$-factor. It is essential that PMC should exert influence on the physical and physicochemical properties of PCS including dark and photo- 
induced conductivity, absorption spectra, luminescence and reactivity. This influence on the properties of conjugated substances forming complexes with PMC was discovered in 1962 in our laboratory and called the effect of local activation'.

At the present time two assumptions about the nature of paramagnetism in PCS are of a great importance among others:

(1) the biradical hypothesis ${ }^{3,8-10}$ which considers PMC as a result of the local decay of $\pi$-bonds in polyconjugated macromolecules with the longest chain. With respect to this hypothesis $\mathrm{S}-\mathrm{T}$ transition may be realized due to thermal excitation and the resulting triplet can be transformed into a biradical. It has also been assumed that the probability that these transitions will occur is connected with a small value of the energy gap in packing like associates of fractions of the polymer homologues with long conjugated chains, with the breach of coplanarity and the gain in resonance energy due to delocalization of the unpaired spin along the system of conjugation.

(2) the hypothesis about the predominant role of electron charge transfer based on the assumption of the presence of close-situated energy levels in PCS. According to this hypothesis charge transfer proceeds via one-electron intermolecular transfer leading to the formation of a stable ion-radical complex ${ }^{11,12}$.

The second hypothesis cannot be considered as the foundation of the general theory of PCS paramagnetism because it does not explain some experimental facts ${ }^{13}$ including the absence of the contribution of dielectric relaxation in polymer hydrocarbons with a system of conjugation ${ }^{10}$.

Moreover, according to quantum-chemical calculations, the one-electron transfer is of low probability in non-polar PCS even for chains of infinite length.

The last remark is also true, although to a much smaller degree, for PCS triplet excitation which is the base of the biradical hypothesis.

We suppose that the general theory for paramagnetism of PCS may be worked out by means of a model of the paramagnetic chain processes ('paramagnetic chains') which will be considered below. According to this model the triplet excitation is a primary act leading to the formation of stable biradicals or ion-radicals (polar media). These processes proceed with low probability at reasonable values of the PCS energy gaps. For example, the probability of occurrence of a triplet population does not exceed $10^{-15}$ and $10^{-22}$ at room temperature and at the energy of $\mathrm{S}-\mathrm{T}$ transition, $E_{\mathrm{ST}}=20$ to $40 \mathrm{kcal} / \mathrm{mol}$. The resulting $\mathrm{PMC}$ are rather stable macromolecular compounds with free spins delocalized along extensive blocks of conjugation.

In real systems macromolecules of PCS are bound in $\pi$-complexes and so the resulting free spins interact also with $\pi$-electrons of the complex-forming chains, but with a smaller exchange frequency. In these "complexes with spin transfer', the probability of $\mathrm{S}-\mathrm{T}$ transition increases and the value of the energy gap apparently decreases.

At corresponding energy expenditures this fact leads to the decay of the $\pi$-bond in such complexes under the influence of the primary spin, i.e. to the effect of local activation.

As a result one spin initiates the formation of two new ones. This leads 


\section{A. A. BERLIN}

to the propagation of a greatly branched chain process. We called this process 'branched paramagnetic chain'.

Owing to the branched-chain character of the reaction and to the high value of the pre-exponential factor $\left(\geqslant 10^{13}\right.$ to $\left.10^{15} 1 / \mathrm{s}\right)$, the process rate steadily increases until it becomes a 'paramagnetic' avalanche; as a result stable PMC are accumulated, which allows their detection by EPR at rather low temperatures.

It is necessary to note the existence of a relationship between the rate of formation, the nature of the polymer and the kinetics of paramagnetic chains.

As PMC are accumulated, two processes take place: the first is PMC 'recombination' with the formation of spin-spin complexes ${ }^{14}$ and the second is PMC decay, i.e. chain termination because of polyconjugation cleavage and spin inactivation in reactions with admixtures.

Disregarding the kinetics of PCS formation the general data about branched paramagnetic chains may be represented by the following simplified scheme:

The formation of primary PMC

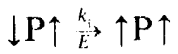

The formation of a complex with spin transfer and the propagation of the branched chain

$$
\begin{gathered}
\mathrm{P} \uparrow+\uparrow \mathrm{P}_{1} \downarrow \stackrel{k}{\rightleftarrows}\left[\mathrm{P} \uparrow_{\ldots}^{\cdots} \downarrow \mathrm{P}_{1} \uparrow\right] \stackrel{k_{E}}{\rightleftarrows} \mathrm{P} \uparrow+\uparrow \mathrm{P}_{1} \uparrow \\
\mathrm{P}_{1} \uparrow+\uparrow \mathrm{P}_{2} \downarrow \stackrel{k^{\prime}}{\rightleftarrows}\left[\mathrm{P} \uparrow_{\ldots}^{\ldots} \mathrm{P}_{2} \uparrow\right] \underset{E}{\stackrel{k_{3}}{\rightleftarrows}} \mathrm{P}_{1} \uparrow+\uparrow \mathrm{P}_{2} \uparrow \text { etc. }
\end{gathered}
$$

The deceleration of the propagation due to spin-spin complex formation

$$
\uparrow P_{1} \uparrow+\uparrow P_{2} \uparrow \stackrel{k_{b}^{\prime}}{\rightleftarrows}\left[\uparrow P_{1} \uparrow \ldots \downarrow P_{2} \downarrow\right]
$$

The termination of the paramagnetic chain due to the cleavage of conjugation or spin inactivation

$$
\mathbf{P}_{\mathbf{i}} \uparrow+\mathbf{x} \stackrel{k}{\rightarrow} \mathbf{P}_{\mathbf{i}} \mathbf{x}
$$

In this scheme the following symbols have been used: $P_{i}$ are molecules of PCS with $i$ links in the block of effective conjugation, arrows $\uparrow \downarrow$ and $\uparrow \uparrow$ mark the ground and triplet states (or stable biradical) correspondingly; $\mathrm{x}$ denotes molecules of the admixture which are capable of reacting with the spins of a stable radical; $k_{\mathrm{i}}, k_{\mathrm{s}}, k_{\mathrm{a}}, k_{\mathrm{b}}, k_{\mathrm{t}}$ are rate constants of the formation of primary centres, the formation of the complex 'spin- $\pi$-bond', the formation of biradicals under local activation (reaction 2), deceleration and decay of PMC, respectively.

In the first approach, the kinetics of the PMC accumulation may be expressed by the equation

$$
\mathrm{d}[\mathrm{PMC}] / \mathrm{d} t=k_{\mathrm{i}}[\mathrm{PCS}]+k_{\mathrm{a}}[\mathrm{PMC}][\mathrm{PCS}]-k_{\mathrm{h}}[\mathrm{PMC}]^{2}-k_{\mathrm{t}}[\mathrm{PMC}] \mathrm{x}
$$

where $k_{\mathrm{h}}=K \times k_{\mathrm{a}}$, and $K$ is the equilibrium constant of the spin complex (reaction 4). Under the quasi-stationary conditions $(\mathrm{d}[\mathrm{PCS}] / \mathrm{d} t=0)$, 
integration of equation 6 gives:

$$
[\mathrm{PMC}]=\frac{(\gamma / a)^{\frac{1}{2}}\left\{c+\exp \left[-2(\gamma a)^{\frac{1}{2}} t\right]\right\}}{c-\exp \left[-2(\gamma a)^{\frac{3}{2}} t\right]}+\frac{b-d}{2 a}
$$

where: $a=k_{\mathrm{b}} ; b=k_{\mathrm{a}}[\mathrm{PCS}] ; \gamma=k_{\mathrm{i}}[\mathrm{PCS}]+(b-d)^{2} / 4 a ; d=k_{\mathrm{t}}[\mathrm{x}] ;$ and $c$ is the constant of integration which can be determined from the initial conditions.

The analysis of expressions 6 and 7 shows the following features:

(1) The curve of PMC accumulation has an $\mathbf{S}$-type form typical of autocatalytic processes.

(2) At $t \rightarrow \infty$, the PMC concentration reaches the limiting value $[\mathrm{PMC}]_{\infty}$ $=(\gamma / a)^{\frac{1}{2}}+(b-d) / 2 a$ which does not depend on the initial concentration of PMC, i.e. [PMC] $]_{0}$.

(3) The spin accumulation rate increases in the region of autoacceleration with increasing $[\mathrm{PMC}]_{0}$, i.e. the effect of local activation becomes apparent in the process.

(4) The linear (or bimolecular) termination (reaction 5) leads to an increase in the induction period and to a decrease in the limiting value of the PMC concentration.

(5) The decrease of the deceleration rate (reaction 4) must lead to an increase of [PMC] and to a decrease in the number average molecular weight with increase in temperature. Indeed, under such conditions the equilibrium constant of the spin complex decreases, and consequently, cracking of such quasi-molecules with the formation of stable radicals takes place.

(6) If the reaction of chain termination (reaction 5) contributes markedly to the process, then other things being equal, the rate of PMC accumulation and its temperature dependence depend on the relation between the deceleration and termination rate constants.

The ideas presented above even in an approximate form are in good agreement with well-known experimental facts. For example, it has been shown that the kinetics of PMC accumulation for PCS synthesis of polymer thermolysis is really described by $\mathbf{S}$-shaped autocatalytic curves which go to a limit. This fact is illustrated by Figures 1 and $2^{15,16}$ and is in complete

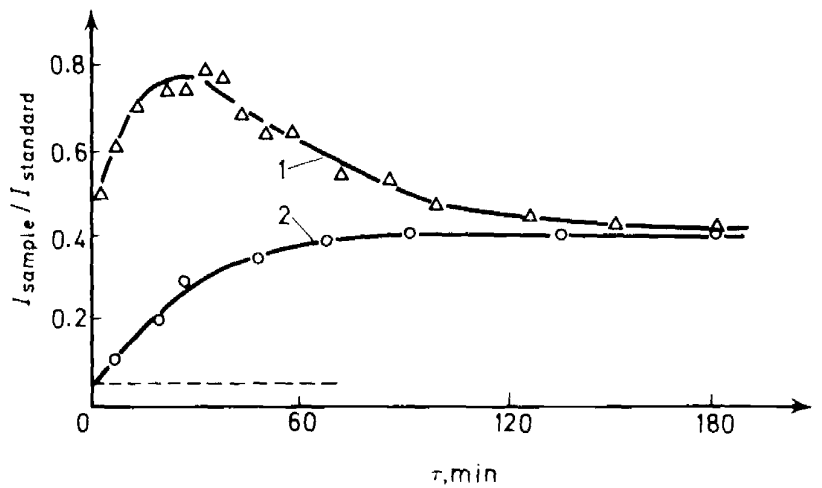

Figure 1. The dependence of the relative e.p.r. signal for thermal polymerization of phenylacetylene on time $t(\mathrm{~min}):(1)$ in resonator; (2) after cooling in air for five minutes. 


\section{A. A. BERLIN}

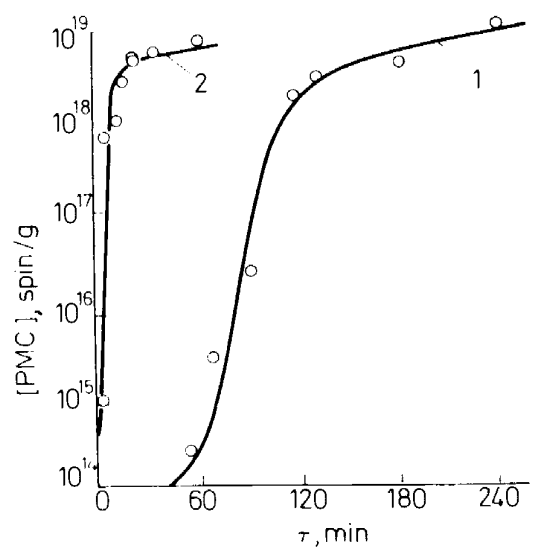

Fiqure 2. The kinetics of PMC accumulation in anthracene thermolysis at $T=450^{\circ} \mathrm{C}$ (vacuum $10^{-5} \mathrm{~mm} \mathrm{Hg}$ ): (1) anthracene: (2) anthracene with addition of one per cent of polyanthracene containing $5 \times 10^{17} \mathrm{spin} / \mathrm{g}$.

agreement with our theory. Figure 2 illustrates also the activation of anthracene thermolysis by the paramagnetic fraction. As we can see, the induction period of PMC accumulation for anthracene dehydropolymerization may be practically excluded due to ELA.

At the present time, a great number of experimental facts exist to demonstrate that ELA appears over a wide range of processes and phenomena such as thermal, thermo- and photo-oxidizing destruction of polymers ${ }^{4}$, catalysis of radical polymerization and some other polyreactions ${ }^{14.15 .17}$, the activation of cis-trans transition ${ }^{21}$ and some other organic reactions ${ }^{22.23}$. The effect of local activation is also reflected in the physical properties of the substance. It affects the activation energy of PCS electroconductivity, the changes of the lifetime of the photocurrent carrier, the value of fluorescence yield, and some other properties ${ }^{24.25}$.

Recently, the influence of spin on the reactivity of stable nitrogen oxyradical $^{26}$ has been detected experimentally, along with the catalytic influence of oxygen on the destruction of aromatic polyamides ${ }^{27}$ and oxygen and nitric oxide catalysis of CCT formation in the interaction between chloroanhydride with tertiary amines ${ }^{28}$.

Apparently, in two latter cases the ELA is realized due to spin complexes of the substrate with such stable gas phase radicals as $\mathrm{O}_{2}$ and $\mathrm{NO}$. It is possible that the ELA will change our views about bioprocesses, and also about oxidation-reduction.

The limit of PMC accumulation predicted by our theory is confirmed by both quantum-chemical calculations and experiments. For soluble PCS it is equal to $10^{20} \mathrm{spin} / \mathrm{g}$.

The possibility of reversible PMC accumulation and its correlation with the decrease of $M_{n}$ has been proved experimentally in our work ${ }^{29}$ and is shown in Figure 3. Apparently, under these conditions the decay is intensified 


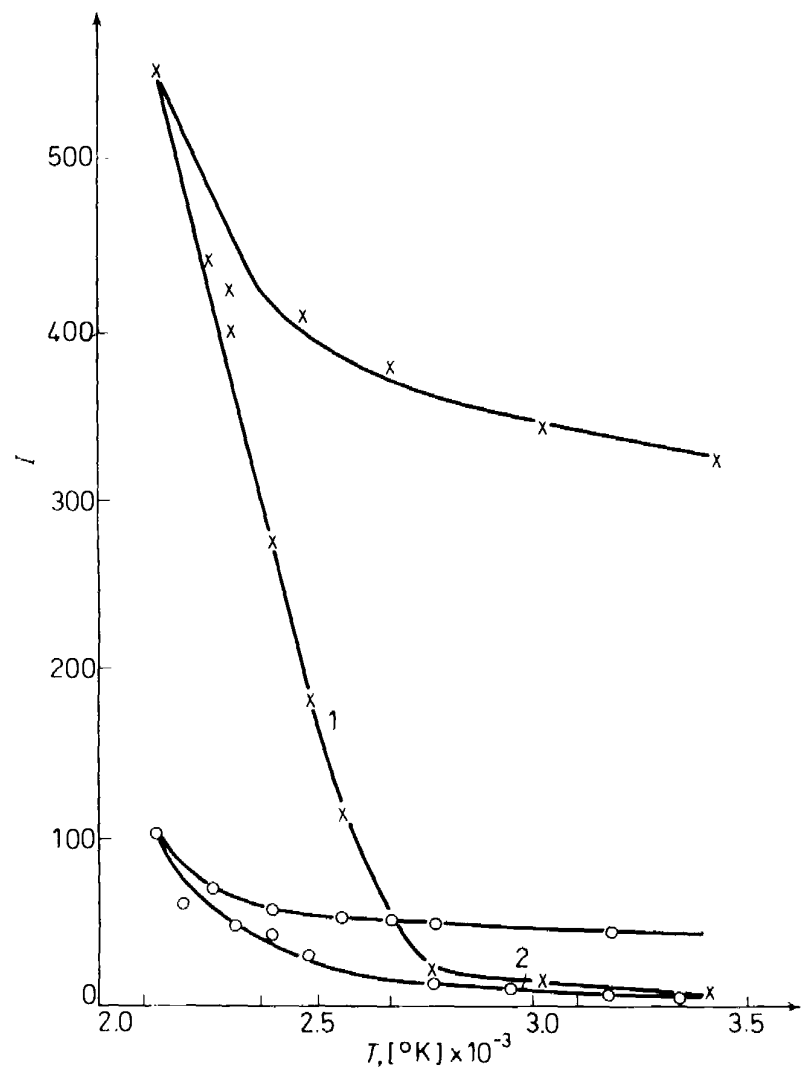

Figure 3. The dependence of e.p.r. intensity of a narrow singlet on inverse temperature for polyphenylacetylene obtained by catalytic and thermal polymerization: (1) polyphenylacetylene obtained by polymerization in the presence of $\left(\mathrm{C}_{2} \mathrm{H}_{5}\right)_{3} \mathrm{AlTiCl}_{3}$ at $T=20^{\circ}$ to $50^{\circ} \mathrm{C}$; (2) polyphenylacetylene obtained by thermal polymerization at $T=150^{\circ} \mathrm{C}$.

as might be expected. This process is more intensive for PCS obtained at a smaller viscosity (i.e. in solutions) and at lower temperatures.

The fact that the reversibility of PMC concentration is not complete may be explained by the structural peculiarities of PCS, causing a high value of the relaxation time $^{30}$.

At the present time we have only preliminary experimental data confirming the predictions of the theory about the reversible changes in the number average molecular weight of PCS with moderate heating. Nevertheless, the comparison of this process proceeding in air and in a vacuum (see Figure 4) clearly shows the role of PMC inactivation by oxygen preventing spin-spin complex formation (see above, reaction 4). This makes it possible to observe the decrease in $M_{n}$ determined at room temperature.

It seems to us that all that has been described above shows that the combination of the effect of local activation with Semenov's theory of branched 
A. A. BERLIN

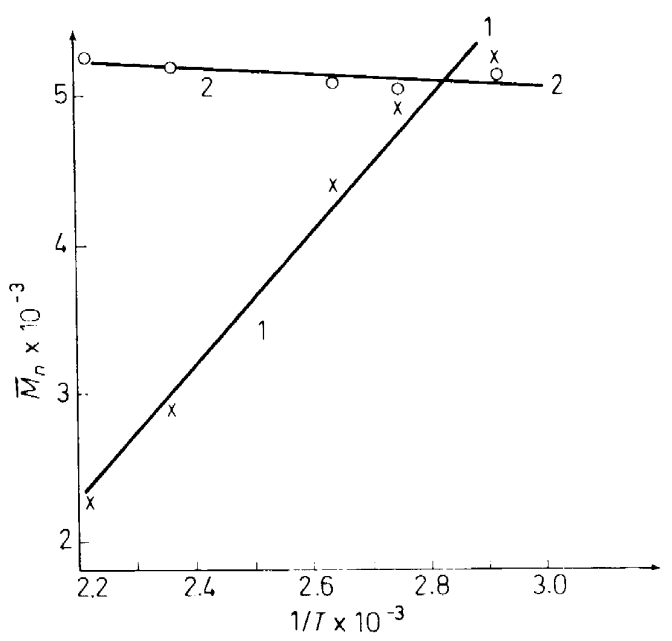

Figure 4. The dependence of the molecular weight of polyphenylacetylene obtained by catalytic polymerization on the temperature of treatment: (1) in air, (2) in a vacuum.

chains is very fruitful for the solution of the fundamental problems in the chemistry of polyconjugated systems, and also-as will be shown belowfor the understanding of catalysis and the inhibition of chemical transformations in thermolysis and thermo-oxidation of low molecular and high molecular weight compounds.

\section{THE FORMATION AND THE ROLE OF PCS IN THERMOLYSIS AND THERMO-OXIDATION}

As has been shown above, some finite probability exists of transforming organic substances into polyconjugated polymer compounds in the case of an appropriate thermal action. This transformation has been investigated for benzene and some aromatic hydrocarbons with condensed rings (anthracene, bianthryl, pyrene, etc.). For example, the autocatalytic accumulation reaction of paramagnetic oligomers $\left(M_{n}=1200-14000\right) . C_{\mathrm{PMC}}=(3-8) \times$ $10^{17} \mathrm{spin} / \mathrm{g}$ with anthronylene links proceeds in anthracene thermolysis in a vacuum or in an inert atmosphere at $T=400^{\circ}$ to $450^{\circ} \mathrm{C}$. The investigation of the chemical mechanisms favours Scheme I in this process:

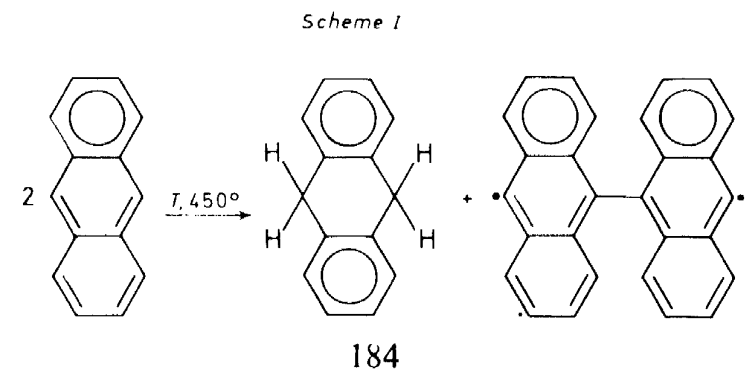


$n$
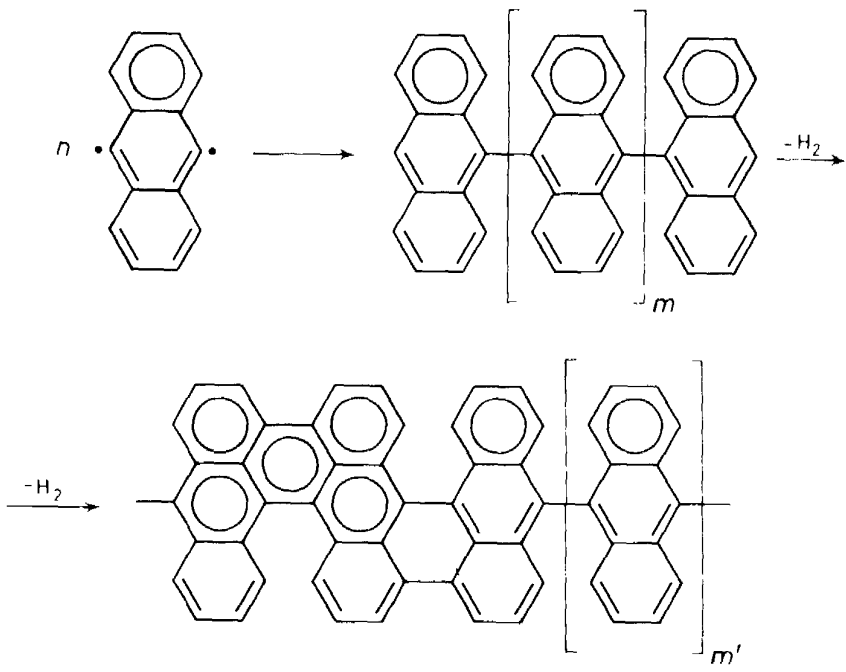

PMC accumulation in the polymer activates the process. This has been proved by the vanishing of the induction period at increasing rates of accumulation due to the introduction of catalytic amounts (up to one per cent) of the soluble polyanthracene paramagnetic fraction.

The investigation ${ }^{15}$ carried out show that the increase in the polymer yield and PMC concentration in the polymer lead to an increase in the gaseous reaction products $\left(\mathrm{H}_{2}, \mathrm{CH}_{2}, \mathrm{C}_{2} \mathrm{H}_{6}, \mathrm{C}_{3} \mathrm{H}_{8}, \mathrm{C}_{2} \mathrm{H}_{4}, \mathrm{C}_{4} \mathrm{H}_{8}\right)$. Apparently, complex reactions of anthracene cracking accompanied by dehydroanthracene dehydration are activated as a result of the effect of local activation.

Electron-donor properties and high radical reactivity of paramagnetic PCS make them able to react with oxygen and radicals, and also to initiate hydroperoxide decay without any yield of radical products ${ }^{2,23}$. Therefore, even small amounts of PCS formed during thermo-oxidation lead to the braking of this process (the effect of 'self-stabilization'). Thus, for example, it is known that thermo-coloured resin-like products formed by the oxidation of lubricating oils are strong inhibitors of their oxidation ${ }^{31}$.

The inhibiting activity of resin-like oxidation products has been described in ref. 32 for dibenzyl thermo-oxidation. The kinetics of 'self-braking' for slow chain reactions of resin-like oxidation products forming in this process has been considered in detail by Emanuel and co-workers ${ }^{33}, 34$.

The authors show that the forming resins inhibit thermo-oxidation of butane and methyl ethyl ketones (see Figure 5). By reason of the correlation between the rates of the decrease in acetaldehyde yield and the increase in resin formation, the authors assume that the inhibiting substance is formed by acetic anhydride polycondensation leading to PCS formation. In connection with this fact, the results of ref. 34 are of great interest. As has been shown in this work, self-braking of propylene oxidation in the presence of acetic anhydride is connected with resin formation. These resins are polyconjugated 


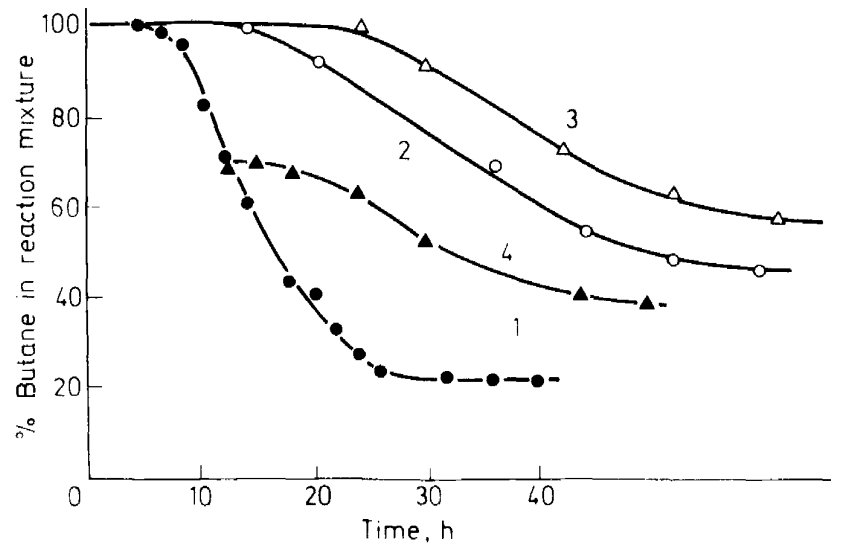

Figure 5 . The influence of resin additions on the kinetics of butane expenditure in thermooxidation ( $\left.145^{\circ} \mathrm{C}, 50 \mathrm{~atm}\right)$ : (1) without additions: (2) $0.9 \mathrm{~g}$ of resin per $1 \mathrm{~mol}$ of butane added at the beginning of the process; (3) the same for $1.8 \mathrm{~g}$ of resin; (4) $0.9 \mathrm{~g}$ of resin per 1 mol of butane added $12 \mathrm{~h}$ after the beginning of the process.

oligomers with a narrow e.p.r. singlet typical of PCS and with PMC concentration $10^{17} \mathrm{spin} / \mathrm{g}$.

Unfortunately, the chemical mechanism of resin formation, typical of the majority of thermo-oxidation processes $\left(T=100^{\circ}\right)$ of low molecular substances, has not so far been investigated in detail. However, we may agree with the authors referred to above that carbonylic compounds forming in the hydroperoxide decay, which proceeds in the presence of metals with variable valence particularly readily, take part in these processes. Scheme II may be proposed as a hypothesis.

At the present time one may consider the existence of two types of paramagnetic particles in the thermolysis of organic polymers at $T>300^{\circ} \mathrm{C}$ to be proved. These types are: (a) stable PMC of biradical nature and forming complexes with diamagnetic chains; (b) rather active $\sigma$-radicals, appearing as a result of bond cleavage in the main chain.

Other things being equal, the ensuing fate of these particles depends on the chemical nature, structure and submolecular organization of the polymer. For very rigid systems $\sigma$-radicals may be accumulated in a large amount because the chemical relaxation of the system leading to their decay (i.e. the combination of $\sigma$-radicals) plays a small part. Such a situation is advantageous for the thermal stability of the system, because the decay of lightly diffusing carriers of radical destruction will be a result of their interaction not only with PMC but also with the 'stuck' $\sigma$-radicals. However, another situation arises for systems where oxygen is present. In this case, for a small chemical relaxation rate, free $\sigma$-radicals interact strongly with oxygen with a large thermal effect (without activation energy) and may not only accelerate thermo-oxidation, but also stimulate thermal ignition of the system at corresponding concentrations.

The experimental data obtained in our laboratory are in complete agreement with all aforesaid and indicate that a trivial cage-effect cannot be 
POLYCONJUGATED SYSTEMS IN THERMAL PROCESSES

Scheme II
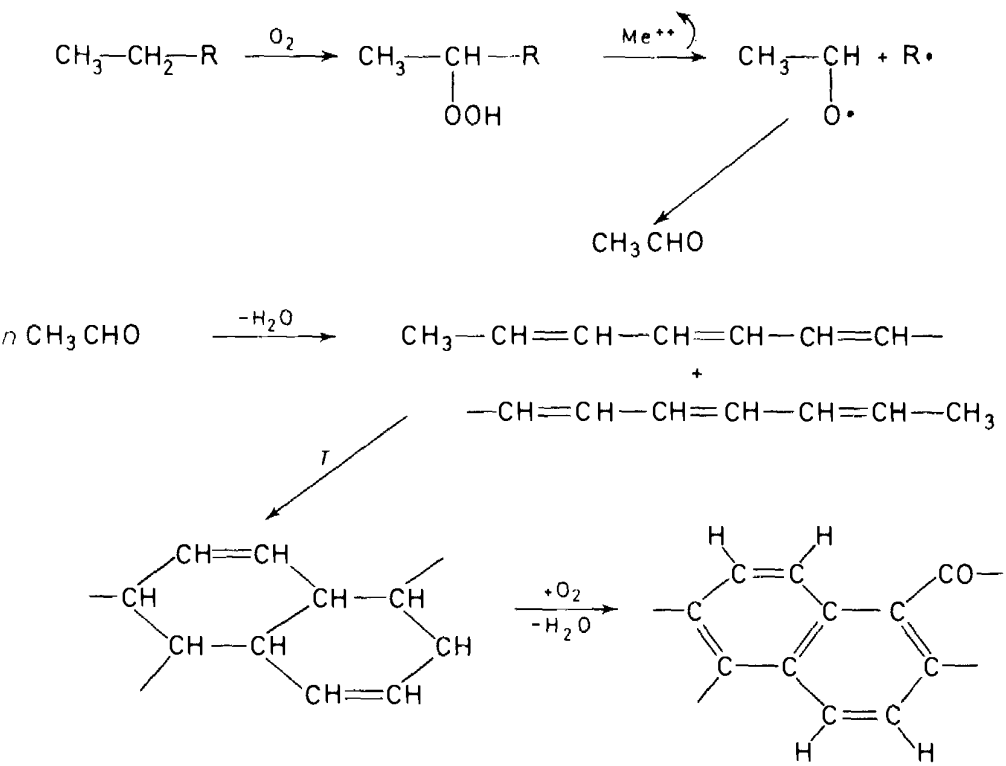

$$
\mathrm{CH}_{3}-\mathrm{CH}_{2}-\mathrm{R} \stackrel{\mathrm{O}_{2}}{\longrightarrow} \mathrm{CH}_{3}-\underset{\mathrm{CH}}{\mathrm{CH}}-\mathrm{R} \stackrel{\mathrm{Me}++}{\longrightarrow} \mathrm{CH}_{3}-\underset{l_{0}}{\mathrm{C}} \mathrm{H}+\mathrm{R} \cdot
$$$$
n \mathrm{CH}_{3} \mathrm{CHO} \stackrel{-\mathrm{H}_{2} \mathrm{O}}{\longrightarrow} \quad \mathrm{CH}_{3}-\mathrm{CH}=\mathrm{CH}-\mathrm{CH}=\mathrm{CH}-\mathrm{CH}=\mathrm{CH}-
$$$$
-\mathrm{CH}=\mathrm{CH}-\mathrm{CH}=\mathrm{CH}-\mathrm{CH}=\mathrm{CH}-\mathrm{CH}_{3}
$$ 


\section{A. A. BERLIN}

applied to PCS or to polymers transforming into these substances ${ }^{35.36}$. For example. it was found that processes leading to the formation of thermocoloured polymers with fragments of condensed aromatic compounds take place in vacuum thermolysis $\left(10^{-3}\right.$ to $\left.10^{-5} \mathrm{~mm}\right)$ of phenolformaldehyde resins and $p$-diethylbenzene crosslinked polymers (or co-polymers) at $450^{\circ}$ to $500^{\circ} \mathrm{C}$. In such systems, the total PMC concentration with the typical narrow e.p.r. singlet ( $3-4$ oersted) reaches $10^{20}$ to $10^{21} \mathrm{spin} / \mathrm{g}$.

It has been found that freshly prepared thermolysis products have the following specificity: (1) their thermo-oxidation at $T=300^{\circ}$ turns into an ignition régime (Figure 6$)^{36,37}$ : (2) they are effective catalysts of the radical polymerization of acrylates and some other electron-acceptor monomers (Figures 7,8$)^{20}$ : (3) their storage in oxygen, argon or in a vacuum, as well as the presence of plasticizers inactivating radicals (for example, dioxydiphenylmethane or phenolalcohols in the case of phenolformaldehyde oligomers) in the thermolysing polymer leads to a decrease in the amount of active radical at the surface by 30 to 40 per cent of the total PMC concentration, a sharp decrease in the oxidation rate and catalytic activity in radical polymerization (Figure 8 ) $^{20.36-48}$.

The influence of crosslinking formation on the thermal and thermooxidizing stability is illustrated by Figure 9 . As we can see, the decrease in molecular mobility in a crosslinked block copolymer indeed causes an increase in thermostability, but considerably reduces stability with respect to thermo-oxidation.

It is necessary to emphasize that the increase in the thermo-oxidation rate and even the transition to thermal ignition at $T \geqslant 300^{\circ}$ to $400^{\circ} \mathrm{C}$ and an increase in oxygen pressure are also possible for fusible and soluble polymers capable of the transformation into PCS after crosslinking has occurred as a result of the preliminary thermal treatment, irradiation, or in the process of

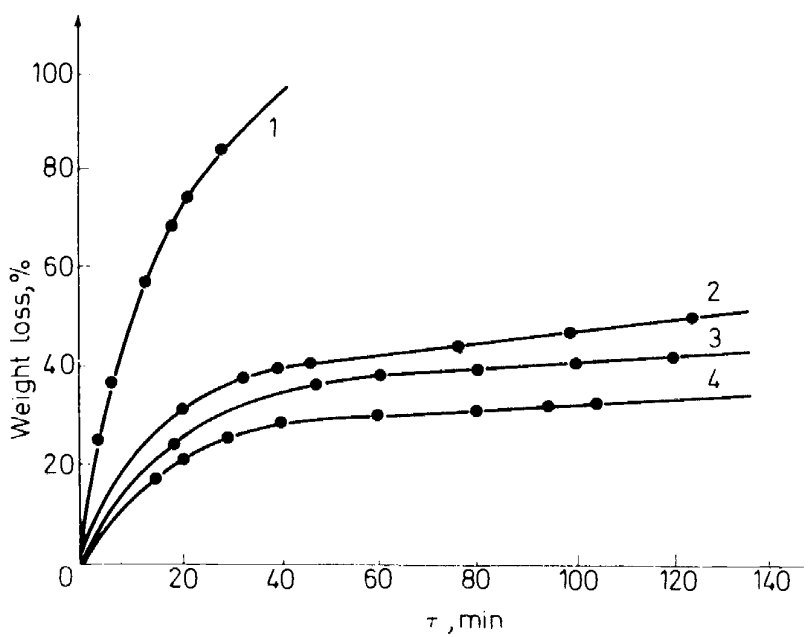

Figure 6. Thermo-oxidizing destruction of thermolysed resin at 300 ' $\mathrm{C}(p=1 \mathrm{~atm})$ : (1) 'fresh' thermolysed resin without phenol alcohol: (2) the same resin after storage in oxygen for 12 hours; (3) the same resin after storage in oxygen for 36 hours; (4) the same resins with phenol alcohols. 


\section{POLYCONJUGATED SYSTEMS IN THERMAL PROCESSES}

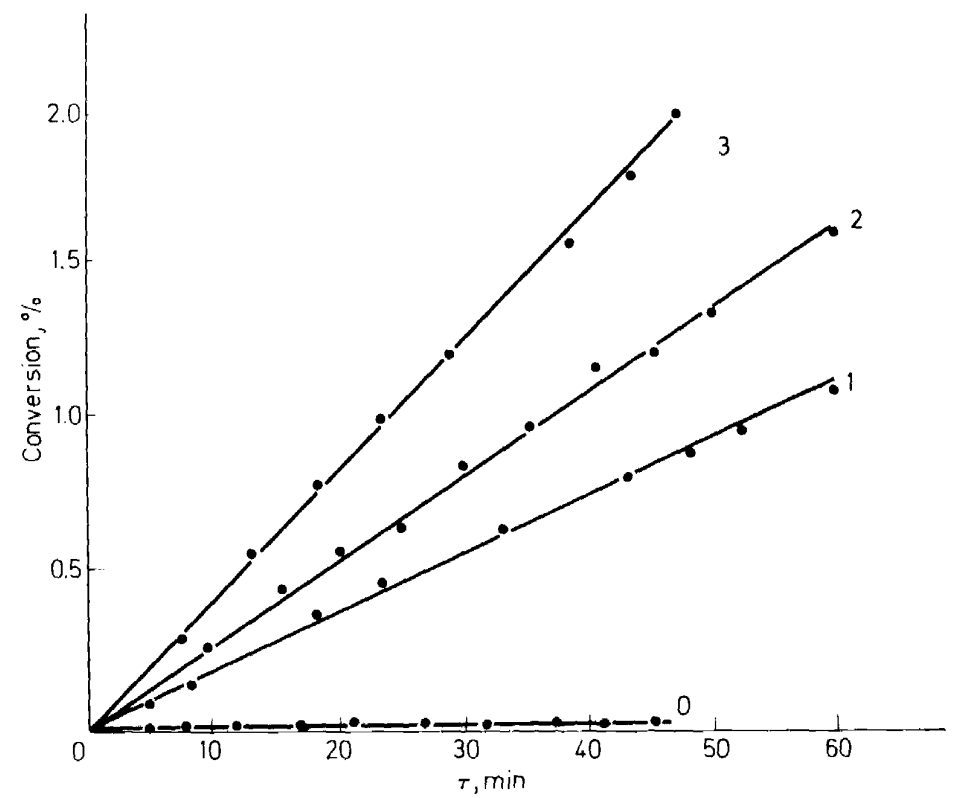

Figure 7. The dependence of the kinetics of polymerization of methylmethacrylate (MMA) catalysed by thermolysed phenolformaldehyde resin without phenol on the concentration of paramagnetic centres: (0) MMA without catalyst; (1) MMA with two per cent thermolysed resin containing $2 \times 10^{18} \mathrm{spin} / \mathrm{g} ;(2)$ the same with $1.7 \times 10^{21} \mathrm{spin} / \mathrm{g} ;(3)$ the same with $5 \times 10^{21}$ $\mathrm{spin} / \mathrm{g}$.

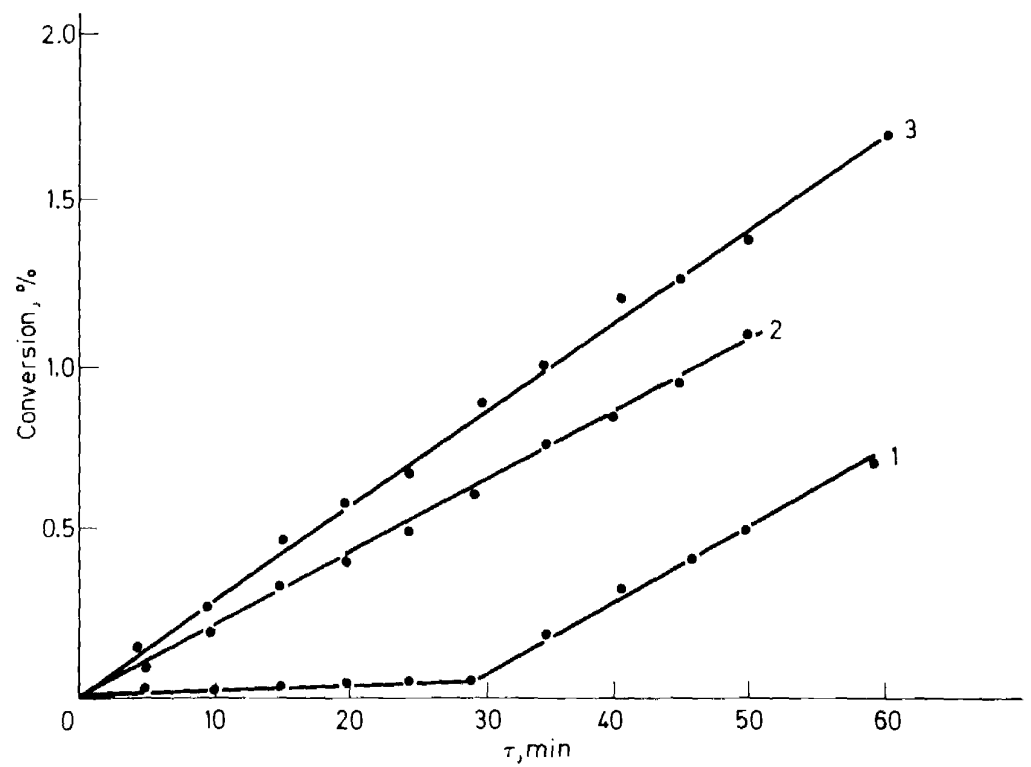

Figure 8 . The change of the catalytic activity of the thermolysed resin(TR) in the polymerization of methylmethacrylate because of storage in air. The duration of keeping: (1) $60 \mathrm{~min}$, (2) $30 \mathrm{~min},(3) 0 \mathrm{~min}$. 


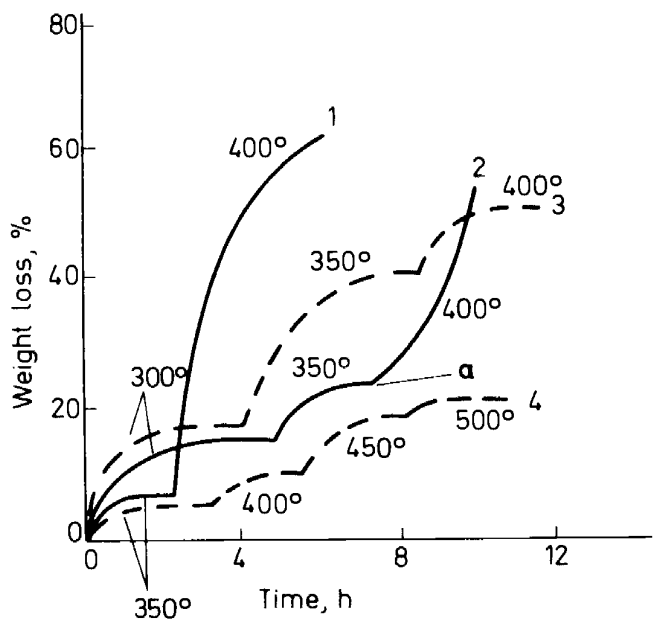

Figure 9. The weight losses of poly-2-methyl-5-ethylpyridine $\left(\bar{M}_{n}=1700\right)$ and its space crosslinked insoluble block copolymer with $n$-diethylbenzene in air and in argon: (1) insoluble block copolymer in air; (2) soluble polymer of 2-methyl-5-ethylpyridine in air; the point a corresponds to the transformation into unmelting insoluble polymer; (3) the same in argon; (4) insoluble block copolymer in argon.

thermo-oxidation (see Figure 10). All these features may be observed not only for polymers without heteroatoms, but also for aromatic polyamides, polyurethanes, aromatic polyesters and various polyheteroarylenes ${ }^{39-41}$ (see Figures 11 and 12).

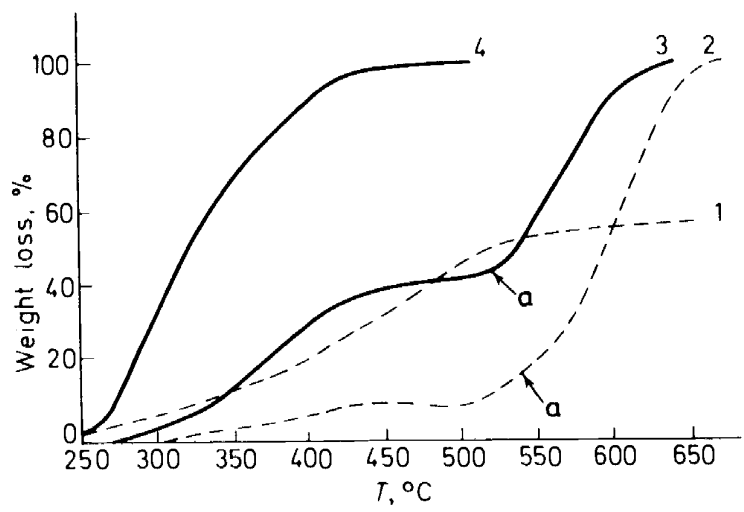

Figure 10. The comparison of thermal and thermo-oxidizing destruction of soluble polyphenylacetylene obtained at $150^{\circ} \mathrm{C}(4,3)$ and $400^{\circ} \mathrm{C}(1,2)$. Curves 2,3 -in air ; 1,4 in a vacuum. In the point a the polymer loses fusibility and solubility. Rate of temperature increase: $3 \mathrm{C}^{\circ} / \mathrm{min}$. 


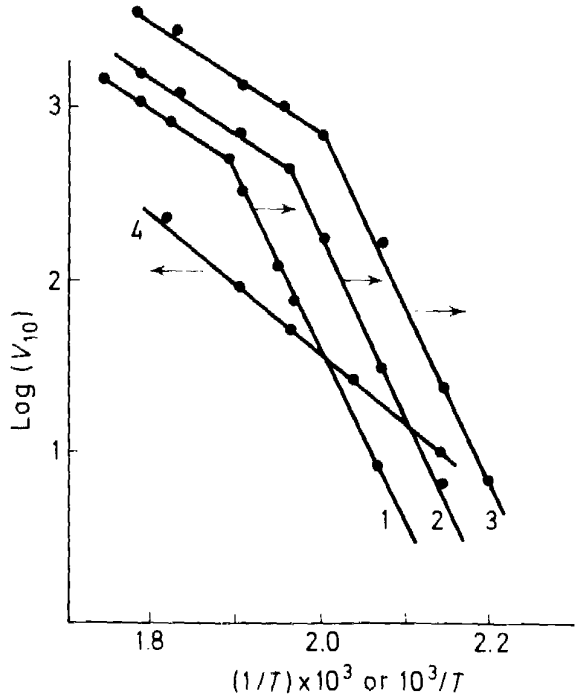

(a)

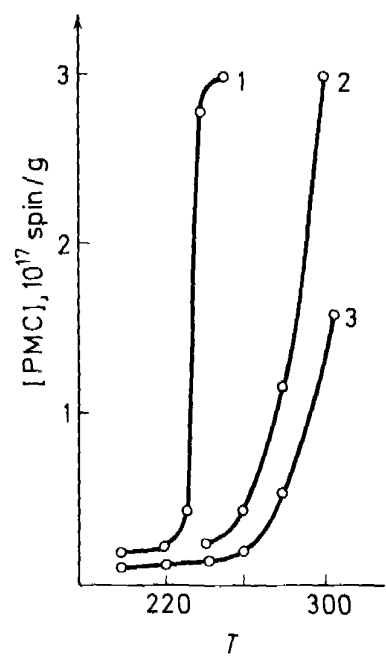

(b)

Figure 11. The kinetics of (a) polyurethane decomposition and (b) PMC accumulation: (1) polyurethane from 2,4-toluene diisocyanate(TDI) and diethylene glycol; (2) the same from TDI and propylene glycol; (3) the same from TDI and ethylene glycol(EG); (4) the same from $\mathrm{TDI}+\mathrm{EG}$ with the addition of thermolysed polyurethane $\left(\sim 10^{17} \mathrm{spin} / \mathrm{g}\right)$. $\left[V_{10}\right.$ is the rate of decomposition of polyurethane.]

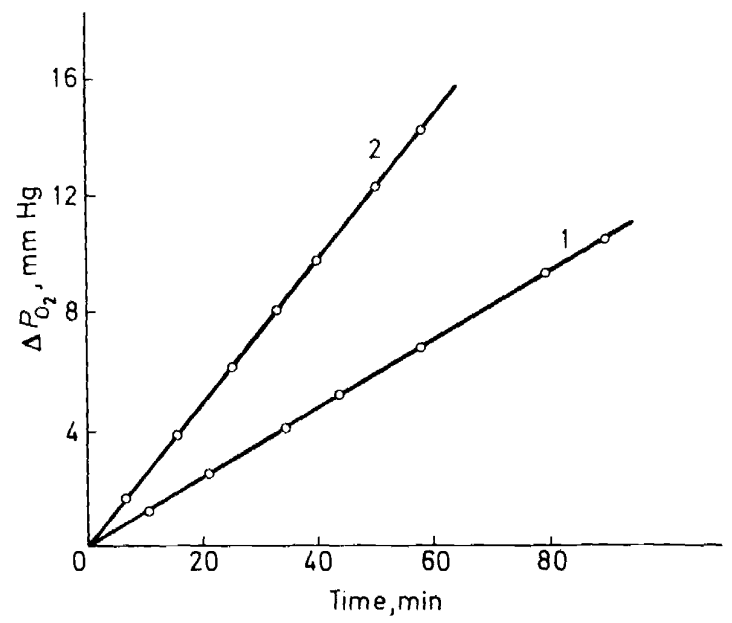

Figure 12. The influence of size of soluble fraction in polyurethane photo-oxidation based on 2,4-toluene diisocyanate and glycol containing PMC on thermo-oxidation $\left(220^{\circ} \mathrm{C}\right)$ of polyurethane from hexamethylenediisocyanate: (1) initial polyurethane from hexamethylenediisocyanate and glycol; (2) the same with one per cent addition of soluble product of toluenediisocyanate-ethyleneglycol polyurethane (thePMC concentration is $10^{18} \mathrm{spin} / \mathrm{g}$ ). 


\section{A. A. BERLIN}

\section{THE FORMATION AND ROLE OF PCS IN INHIBITED THERMO-OXIDATION}

One of the most auspicious methods of PCS synthesis is dehydropolycondensation proceeding usually with radical or ion initiation ${ }^{42}$. A large number of assorted monomers belonging to the class of aromatic hydrocarbons, halogen-substituted phenols, amines, etc. suitable for transformation into polyconjugated polymers at $T \leqslant 200^{\circ}$ to $250^{\circ} \mathrm{C}$ by methods of oxidizing dehydropolycondensation is known now. This suggests an idea that the conditions when low-molecular weight inhibitors with mobile hydrogen atoms are transformed into corresponding PCS by an interaction with oxygen or peroxy radicals may be realized in the inhibited thermooxidation of polymers. In the presence of high-polymer macroradicals, the propagating inhibitor chain may interact with active centres of polymer forming original inoculated co-polymers. These co-polymers must be well combined with a saturated polymer. They take an active part in the inhibition, similarly to polyconjugated oligomers ${ }^{4}$.

All aforesaid may be represented in a general form by the Scheme III :

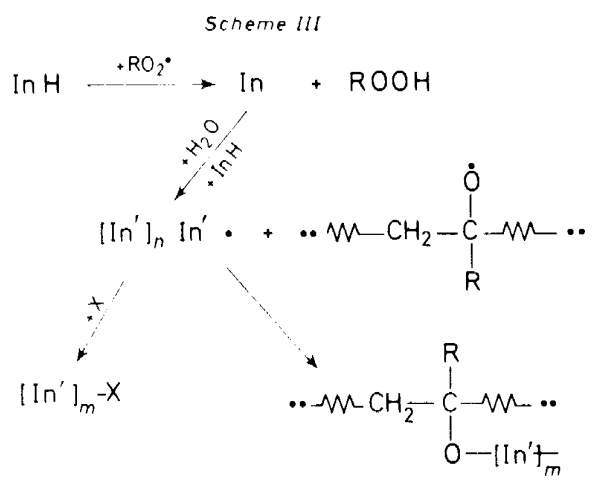

As a result of these processes, products with higher radical reactivity than initial monomer inhibitors are formed because they are characterized by a greater branch conjugation and by the presence of complex bound PMC causing the effect of local activation. Besides, polyconjugated polymers containing PMC have a lower ionization potential and so initiate the decay of hydroperoxide and take part in the process of initiation at high temperatures to a much lesser degree. In connection with this fact it is natural to expect an anomalously high dependence of induction periods on the concentration of the monomer inhibitor, the appearance of the second induction period stipulated by the PCS formed, and an increase in the temperature limit for the application of the inhibitor suited for the above processes.

The experimental data are in complete agreement with these considerations and lead to some conclusions which are of a great scientific and practical interest ${ }^{4}$.

As was emphasized in our work on the braking of the oxidation of paraffins by products of anthracene thermolysis, the oxidizing dehydropolycondensation leading to the formation of coloured polymer products sharply increas- 
ing the inhibitor activity proceeds in the inhibited thermo-oxidation of ceresin $\left(T=180^{\circ}\right.$ to $\left.200^{\circ} \mathrm{C}\right)$ in the presence of anthracene and its complexes with tetracyanoethylene. In this paper we have given evidence for the presence of polyconjugated chains and PMC in such products ${ }^{43,44}$.

Later a report was published ${ }^{45}$ where the authors described high inhibiting activity of coloured compounds forming in the oxidation of p-methylalkylphenols and alkyl-bis-phenols in the inhibited thermo-oxidation $\left(T=200^{\circ} \mathrm{C}\right)$ of polypropylene and co-polymers of tetrahydrofuran with ethylene oxide.

Figure 13 taken from the work carried out by Levantovskaya, Kovarskaya and co-workers ${ }^{46}$ illustrates the accumulation of coloured products of the oxidation of 4,4-methyl-bis(2,6-di-tert-butylphenol) used as the inhibitor within the induction period and the development of thermo-oxidation when the products are transformed into uncoloured substances. These results

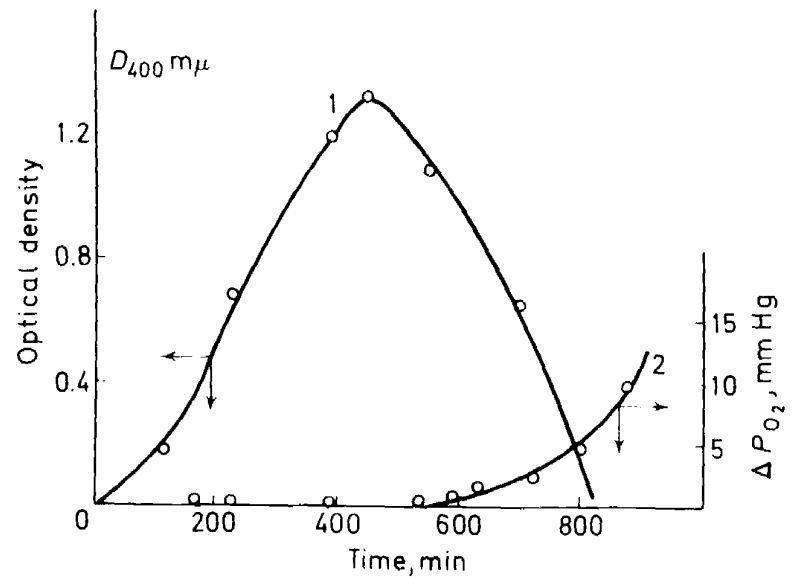

Figure 13. The kinetic curves of the changes in optical density (1) at $\lambda_{\max }=400 \mathrm{~m} \mu\left(D_{400}\right)$ in thermo-oxidizing destruction of tetrahydrofuran-propyleneoxide copolymer in the presence

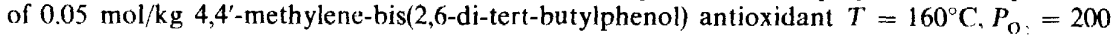
$\mathrm{mm} \mathrm{Hg}$; (2) corresponding change of partial pressure of oxygen.

are in complete agreement with our investigations and with the work carried out by Pospíšil and Gömöry with co-workers, where the increase in inhibiting activity and the existence of the so-called second induction period in the presence of coloured products formed from aromatic amines and alkylphenols within inhibited oxidation of ceresin, rubber, polyethylene, and some other polymers have been demonstrated (see Figures 14, 15) ${ }^{4,47}$.

The data about the synergism of the inhibiting action in mixtures of unoxidized and oxidized amines and phenol stabilizer are of great interest. Such effects have been studied by us and by the cited authors in the following systems: polyan thracene-anthracene ${ }^{4,43}$, polydiphenylamine-diphenylamine $^{4,47,48}$, the unfractionated coloured products of bisphenol and diphenyl$p$-phenylenediamine oxidation separated from monomers and also for the process of thermo-oxidation of paraffins, polypropylene, rubber and polyethylene $\left(T=160^{\circ}\right.$ to $\left.200^{\circ} \mathrm{C}\right)$. 
A. A. BERLIN

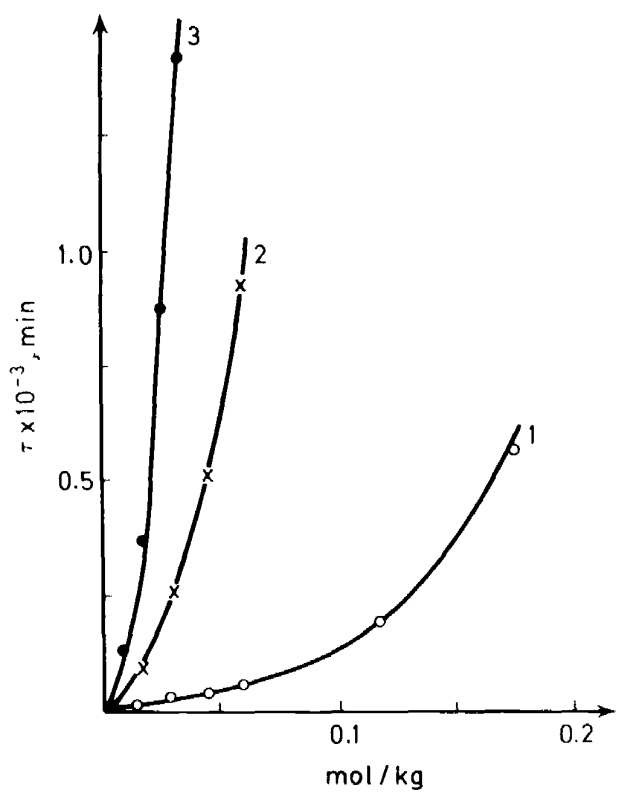

Figure 14. The induction period of ceresin oxidation $\left(T=180^{\circ} \mathrm{C}\right)$ in the presence of diphenylamine (DPA) (1) and polyconjugated products formed in DPA oxidation for six hours (2) and for 15 hours (3).

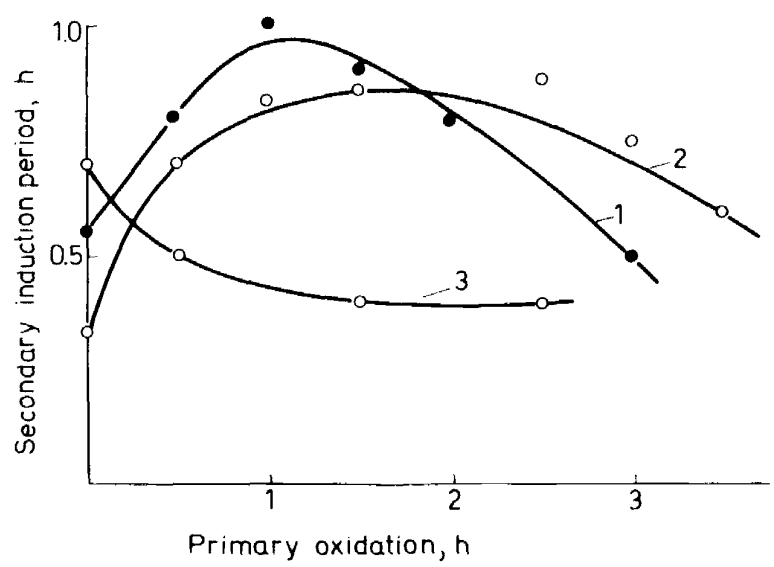

Figure 15. The second induction periods of polyethylene oxidation. Inhibitors: $1-4,4^{\prime}$-dihydroxydiphenyl; $2 \cdots$ phenylcyclohexyl-p-phenylenediamine; $3-N, N^{\prime}$-diphenyl-p-phenylenediamine. 
The mechanism of these processes has been investigated by some authors (for example, see refs. 46, 49, 50) using thin layer chromatography with aluminium oxide and isolation of coloured products by benzene, petroleum ester-ethylacetate with the subsequent application of e.p.r., n.m.r., i.r. and electronic spectrometry and chemical analysis.

It is interesting to note that by using these methods, the authors usually came to the conclusion that an increase in the inhibiting activity was connected with the transition to benzoquinone (phenol oxidation) or quinoneimines (aromatic amine oxidation). However, such results do not agree with Pospísil's data which show a considerable decrease in the benzoquinone inhibiting activity in comparison with hydroquinone ${ }^{51}$, and also with our investigations giving evidence for the formation of polyconjugated oligomers containing PMC in aromatic inhibitor oxidation ${ }^{4}$.

We suppose that the reason for this disagreement resides in the possible isolation of low molecular products only from the absorbent, since the polyconjugated paramagnetic polymer has not been extracted. Indeed, it is well known that it is impossible to isolate the polymer product with the usual solvents for PCS absorption on aluminium or silicone oxide (see for example ref. 13). This is why it is difficult to extract oxidizing polycondensation products by using such methods of fractionation and to estimate this role in thermo-oxidation inhibition.

In connection with this fact, let us consider some data about the inhibiting action and thermo-oxidation of diphenylamine (DPA) and analogues obtained from it. The formation of PMC, the intensification of colour in the induction period and the high limit concentrations have been established by using DPA as the inhibitor of thermo-oxidation $\left(160^{\circ}\right.$ to $\left.220^{\circ} \mathrm{C}\right)$ of ceresin and polymers (rubbers, polypropylene). This justifies the assumption that DPA may be transformed into more active polyconjugated polymer products. The results of works on the isolation of polymer products of oxidation and their investigation confirmed what has been said above and showed that

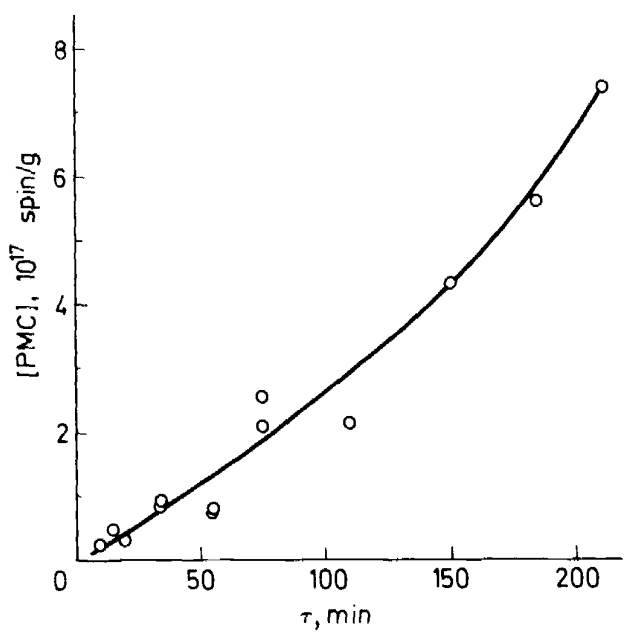

Figure 16.The increase in $\mathrm{PMC}$ concentration in diphenylamine oxidation $\left(220^{\circ} \mathrm{C}, P_{\mathrm{O}_{2}}=1 \mathrm{~atm}\right)$. 


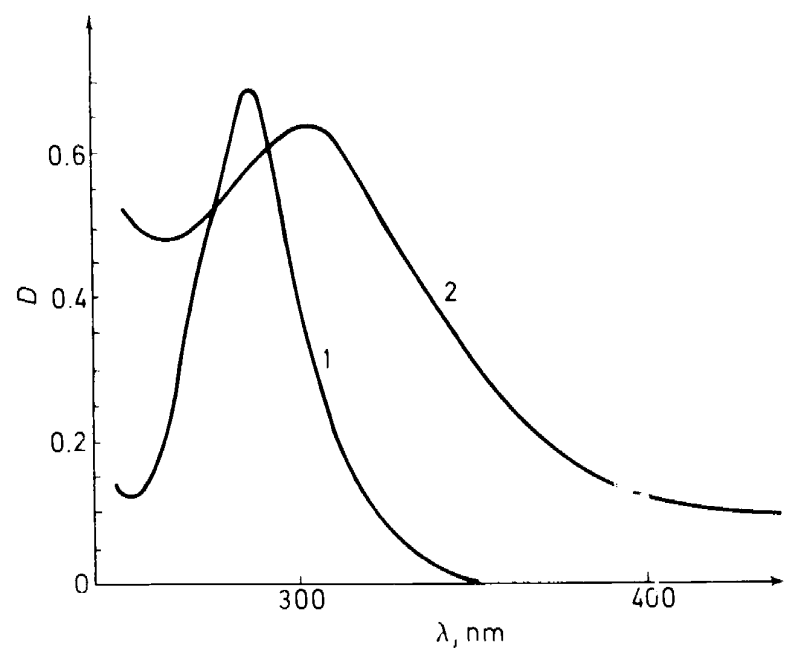

Figure 17. Absorption spectra of monomer (DPA) and polymer obtained by its oxidation $\left(220^{\circ} \mathrm{C}, P_{\mathrm{O}_{2}}=1 \mathrm{~atm}\right):(1) \mathrm{DPA}$ electronic spectrum; (2) the same for PDA with $\bar{M}_{n}=2500$.

it was necessary to investigate the mechanism of DPA oxidation and the properties of polymer products. We investigated also some DPA analogues (phenyl- $\alpha$ and $\beta$-naphthylamines, alkyl and alkylene substituted DPA, diphenyl-p-phenylenediamines).

As has been found, oxidizing dehydropolycondensation accompanied by an autocatalytic increase in PMC concentration and by the formation of coloured polymer products with number average molecular weight from 540 to 2600 and stable PMC concentration from $10^{17}$ to $(3-8) \times 10^{18}$ spin/g takes place in DPA thermo-oxidation (see Figures 16 and 17). Chemical analysis, i.r. and n.m.r. investigations of the polymer formed show the presence of structural elements like

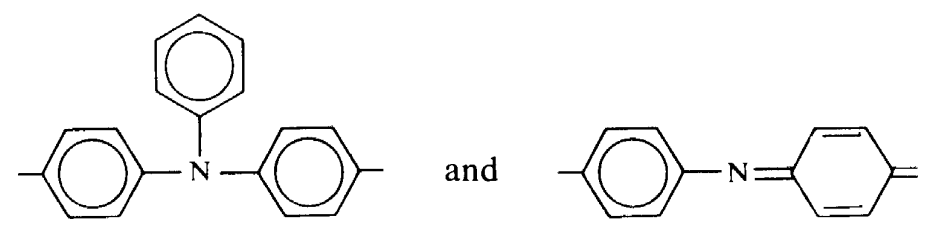

At the same time, the concentration of carbonyl quinone oxygen is very small (one atom per eight to ten links). Taking into consideration all the facts indicated above and also the data on DPA catalytic oxidation ${ }^{48}$, we came to the conclusion that the most probable scheme of the chemical mechanism for dehydropolycondensation is the Scheme IV.

The kinetics of DPA oxidation at $T=225^{\circ}$ to $260^{\prime} \mathrm{C}$ may be seen in Figure 18.

Plotted semilogarithmically the kinetic curve is a straight line till a process depth corresponding to the absorption of 0.6 to $0.7 \mathrm{~g} / \mathrm{mol}$ of oxygen per $1 \mathrm{~g} / \mathrm{mol}$ of DPA. This corresponds to alienation of amine hydrogen and 
POLYCONJUGATED SYSTEMS IN THERMAL PROCESSES<smiles>O=C(CN(c1ccccc1)c1ccccc1N(CCCN=C1C=C[CH+]C=C1)c1ccccc1)c1ccccc1Nc1ccccc1</smiles>

Scheme IV

Hypothetical scheme of oxidative dehydropolycondensation of secondary aromatic amines<smiles>[H][Y9](=O)c1ccc(N=C2C=CC(C)C=C2)cc1</smiles><smiles>CC(C)c1ccc(N(c2ccccc2)C(C)(C)c2ccc(N=C3C=CC(=C4C=CC(=O)C=C4)C=C3)cc2)cc1</smiles>

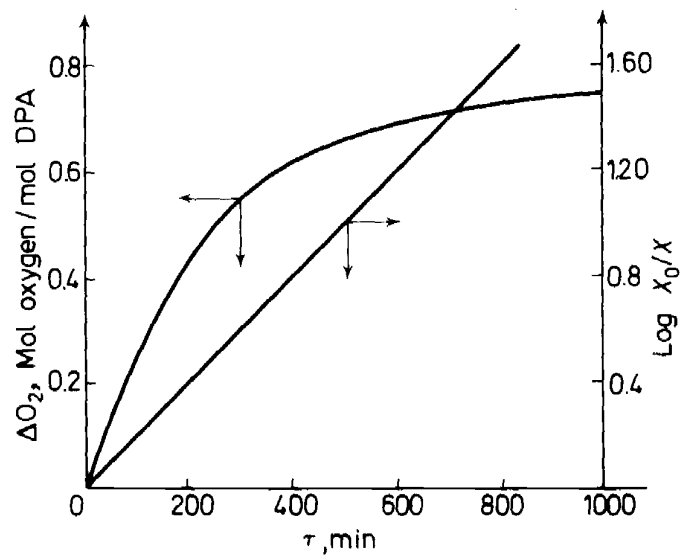

Figure 18. The kinetic curves of oxygen absorption in the oxidation of diphenylamine (DPA) $\left(225^{\circ} \mathrm{C}, P_{0_{2}}=1 \mathrm{~atm}\right)(1)$ and its semilogarithmic anamorphosis (2). $X_{0}=0.75 \mathrm{~mol} \mathrm{O} / \mathrm{mol}$ DPA $: \mathrm{I}=\left(0.75-\Delta \mathrm{O}_{2}\right) \mathrm{molO}_{2} / \mathrm{mol}$ DPA. 
$\mathrm{H}$-atom in the phenyl ring. The effective activation energy for oxidation is $20 \mathrm{kcal} / \mathrm{mol}$.

Polyconjugated polymers isolated in this stage are easily soluble and fit in with the above-mentioned characteristics. The interaction of oxygen with $\mathrm{H}$-atoms at the position ortho with respect to amine nitrogen begins to play a considerable part at deeper oxidation. As a result, the chain branches and this leads to space crosslinking. Along with this, it has been established that insoluble products are already formed in the early stages of oxidation of $4,4^{\prime}$-dialkyl or $4,4^{\prime}$-oxyderivatives of DPA proceeding at a higher rate where the oxygen attack is directed at both $\mathrm{H}$-groups, hydrogen in benzene, and the alkyl groups. Analogous results have been obtained for the joint co-oxidation of DPA with its $4,4^{\prime}$-disubstituted derivative.

It has been found that there is a catalytic influence of PMC ([PMC] $\leqslant$ $\left.(3-5) \times 10^{18} \mathrm{spin} / \mathrm{g}\right)$ appearing as a result of oxidizing DPA dehydropolycondensation (polydiphenylamine-DPA) on the kinetics of its oxidation. We have demonstrated that PDA added to DPA reduces the induction period of diphenylamine oxidation (Figure 19). As we can see, it is necessary to take into consideration the effect of local activation in this case too.

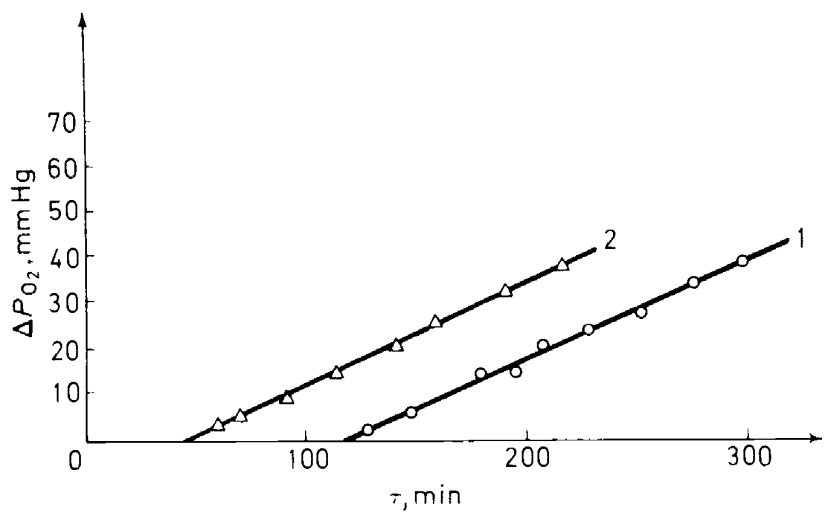

Figure 19. The dependence of induction period and initial rate of oxygen absorption in diphenylamine oxidation $\left(225^{\circ} \mathrm{C}, P_{\mathrm{O}}=1 \mathrm{~atm}\right)$ on the addition of polydiphenylamine $\left(\bar{M}_{n}=2000\right.$, the PMC concentration is $5 \times 10^{18} \mathrm{spin} / \mathrm{g}$ ). (1) diphenylamine; (2) the $1: 4$ mixture of polydiphenylamine $\left(\bar{M}_{n}=2400\right)$ with diphenylamine.

The PDA inhibiting activity in thermo-oxidation is usually higher than that of DPA. However, the application of mixtures without monomers of PDA with DPA has a greater effect. This situation is illustrated in Figure 20. These curves show that the observed effects of synergism are connected with the joint action of PCS and monomer inhibitors.

The cause of synergism is apparently connected with the capacity of PDA (as well as other PCS) to initiate hydroperoxide decay without the formation of free radical products in bulk proved by Ivanov, Kobrianski and the author of the present report. One cannot exclude the formation of PMC-DPA spin complexes with the activation of their reactivity due to the effect of local activation.

It should be added that a rather small content of hydrogen of the NH- 


\section{POLYCONJUGATED SYSTEMS IN THERMAL PROCESSES}

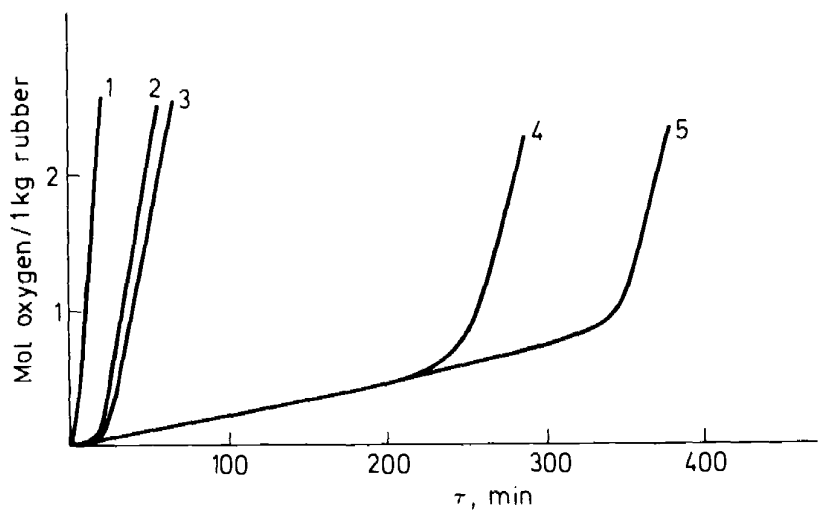

Figure 20. The kinetics of oxygen absorption with 1,4-cis-polybutadiene at $T=150^{\circ} \mathrm{C}$ and $P_{\mathrm{O}_{2}}=1 \mathrm{~atm}$ : (1) without inhibitor; (2) with $0.75 \%$ addition of PDA; (3) with $2.75 \%$ addition of DPA; (4) with $2.0{ }^{\prime \prime}$ addition of PDA; (5) with addition of $0.75 \%$ PDA $+2.25 \%$ DPA.

group in soluble PDA or the absence of 'sticking' active radicals (see above) in such polymers practically exclude their ability to take part in the act of initiation.

Meanwhile, they have a fairly low ionization potential and high radical reactivity and so they are the effective electron donors with respect to oxygen and hydroperoxides; they destroy them and react with the products of radical decay.

The capacity of PDA to exhibit synergistic effects in mixtures with various substances including dilanoylthiodipropionate, trinonylphenylphosphite (oxidation of nitrile rubber SKN-26), anthracene (oxidation of ceresin, paraffins, polyolefins) are in complete agreement with all aforesaid (see Figure 2I).

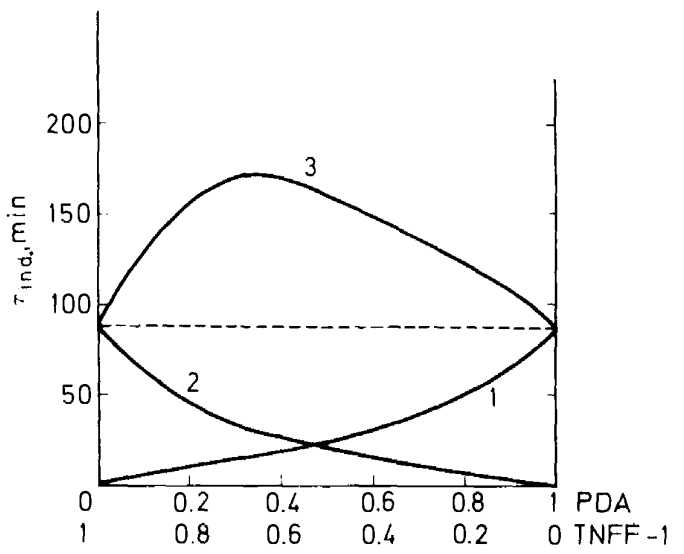

Figure 21. The dependence of induction period in nitrile rubber (SKN-26) oxidation on the content of binary mixture PDA $\left(\bar{M}_{n}=2050\right)$ with Polygard at constant total concentration of components. The inhibitor concentration $0.06 \mathrm{~mol}$ link of PDA per kg of rubber at $P_{\mathrm{O}_{2}}=760$ $\mathrm{mm} \mathrm{Hg}, T=160^{\circ} \mathrm{C}$. (1) separately introduced PDA; (2) separately introduced Polygard (trinonylphenylphosphite--TNFF); (3) mixture of PDA and Polygard. 


\section{JOINT TRANSFORMATION OF POLYMERS AND POLYCONJUGATED ANTIOXIDANT IN INHIBITED THERMO-OXIDATION}

As has been emphasized above for thermo-oxidation of many polymers, the intensification of colour as a result of the formation of polyconjugated regions (or PCS) outstrips or coincides with autobraking of the process. The data obtained allow us to state that 'self-stabilization' is connected with the inhibiting role of PCS.

On the other hand, we have come to the conclusion that monomer antioxidants are also able to form oligomers due to radical polyreactions under the conditions of inhibited thermo-oxidation.

The comparison of these facts allows the drawing of a conclusion about the possibility of an interaction between propagating the inhibitor chain with active centres of oxidizing polymer macromolecules. This process has been investigated by Kovarskaya, Livertovskaya and co-workers for the case of tetrahydrofuran-propylene oxide co-polymer thermo-oxidation inhibited by bisphenols ${ }^{46}$.

In our laboratory this process has been investigated by Ivanov for atactic polypropylene oxidation $\left(T=160^{\circ}\right.$ to $200^{\circ} \mathrm{C}$ and $\left.\mathrm{P}_{\mathrm{O}_{2}}=760 \mathrm{~mm} \mathrm{Hg}\right)$ inhibited by anthracene $e^{4,52}$.

The data obtained give rise to a conclusion about the formation of a thermodynamically more stable polyene conjugated system by atactic polypropylene thermo-oxidation at rather high temperature which may be partially aromaticized by thermal effects.

Taking all this into consideration, it is logical to assume that radicals formed in inhibitor oxidation may react with $\alpha$-hydrogen of the $\mathrm{CH}_{2}$ groups conjugated with polyene chains or with active centres which appeared as a result of the reaction with oxygen.

To elucidate the nature of the transformations, the product of polypropylene oxidation in the presence of $0.8 \mathrm{~mol} / \mathrm{kg}$ of anthracene at $225^{\circ} \mathrm{C}$

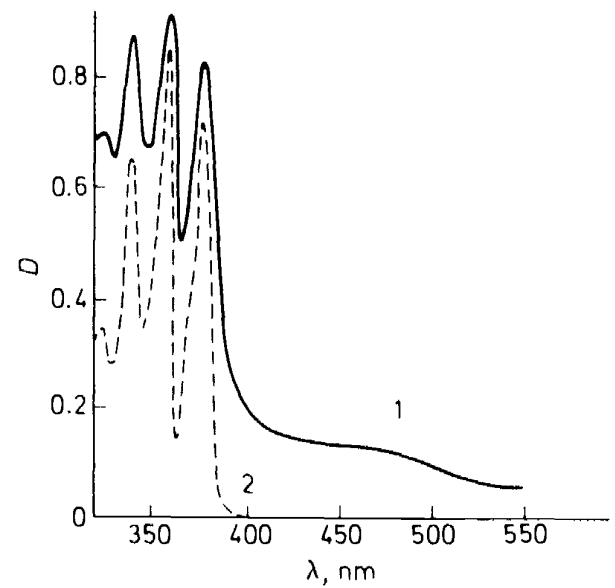

Figure 22. Absorption spectra of polypropylene-anthracene co-oxidation product (fraction S-1, curve 1) and an thracene (curve 2). 
was accumulated within $100 \mathrm{~min}$. The oxidized mixture was separated into two fractions soluble (S) and insoluble (IS) in cold heptane. Brown and dark bruwn benzene soluble (S-1) and insoluble (IS-1) fractions were obtained by the following more delicate fractionation by vacuum-distillation at $130^{\circ}$ to $150^{\circ} \mathrm{C}\left(10^{-5} \mathrm{~mm} \mathrm{Hg}\right)$ and treatment in boiling benzene. There are three absorption bands in the region $2840-2960$ and $1460 \mathrm{~cm}^{-1}$ in the i.r. spectrum of S-1 which have been attributed to the $\mathrm{CH}_{3}$ and $\mathrm{CH}_{2}$ group absorption. Moreover, several bands corresponding to anthracene $(1625,1450,1385$, $959,888,727 \mathrm{~cm}^{-1}$ ) have been observed. Anthraquinone bands have not been found. The spectra of both fractions have a considerable absorption background, the most intensive background absorption being observed for the benzene-insoluble fraction IS-1. The insoluble fraction IS-1 absorption bands are rather wide without narrow maxima. Nevertheless, one has a good basis to affirm the presence of aromatic polyconjugated structures (absorption at $750-900$ and $1600 \mathrm{~cm}^{-1}$ ), and also polyene blocks of conjugation formed from polypropylene and containing lateral $\mathrm{CH}_{3}$ groups.

The electron absorption spectrum of the benzene-soluble fraction S-1 is shown in Figure 22. It contains absorption bands typical of anthracene $(340,360,378 \mathrm{~m} \mu)$ and a sufficiently intense long-wave background absorption without maxima.

Fractions S-1 and IS-1 have a narrow symmetrical e.p.r. signal (the PMC concentration is $6 \times 10^{17} \mathrm{spin} / \mathrm{g}^{-1}$ for S-1 and $3 \times 10^{18} \mathrm{spin} / \mathrm{g}^{-1}$ for IS-1).

The element analysis gives five per cent of oxygen in S-1.

The data obtained allow us to assume that S-1 and IS- 1 are stable complexes of a polyconjugated polymer with anthracene and products of its transformation. This polymer is formed by thermo-oxidizing destruction of

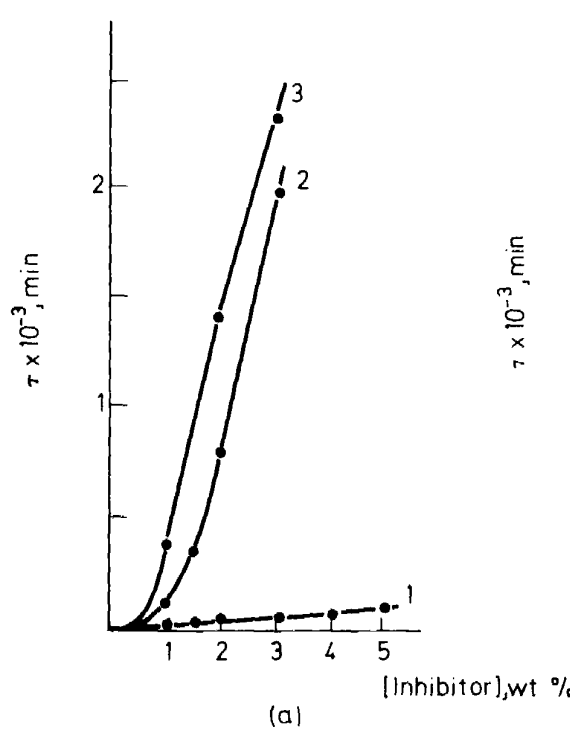

(a)

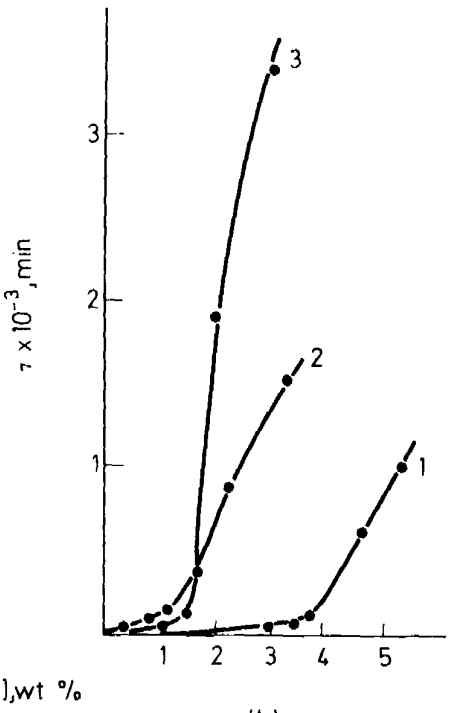

(b)

Figure 23. The induction periods of the thermo-oxidation of ceresin (1) and polypropylene (2) inhibited by anthracene: (a) at $T=160^{\circ} \mathrm{C}$; (b) at $T=180^{\circ} \mathrm{C}$. 


\section{A. A. BERLIN}

Scheme $V$

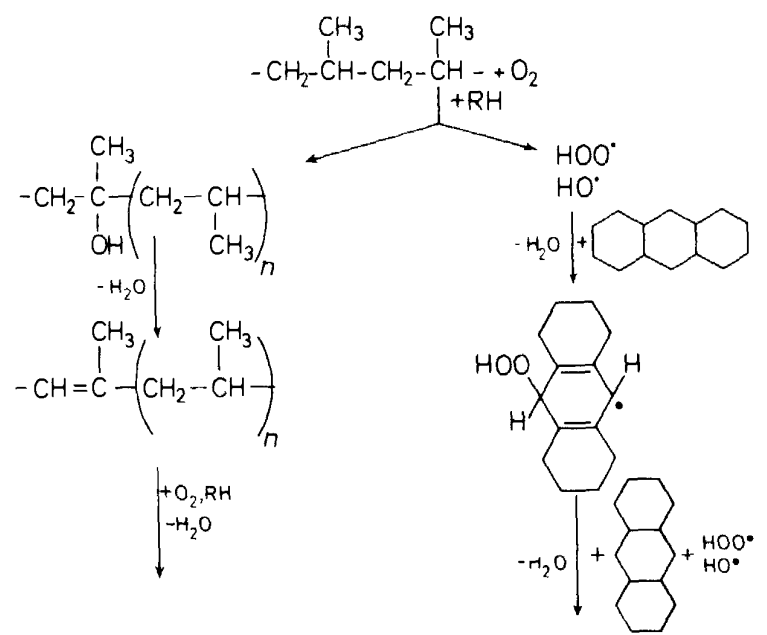

$f\left(\mathrm{CH}=\stackrel{\mathrm{CH}_{3}}{\mathrm{C}}-{ }_{\mathrm{CH}}=\stackrel{\mathrm{C}}{\mathrm{C}}-\left(\mathrm{CH}_{2}-\stackrel{\mathrm{CH}_{3}}{\mathrm{CH}}-\right.\right.$
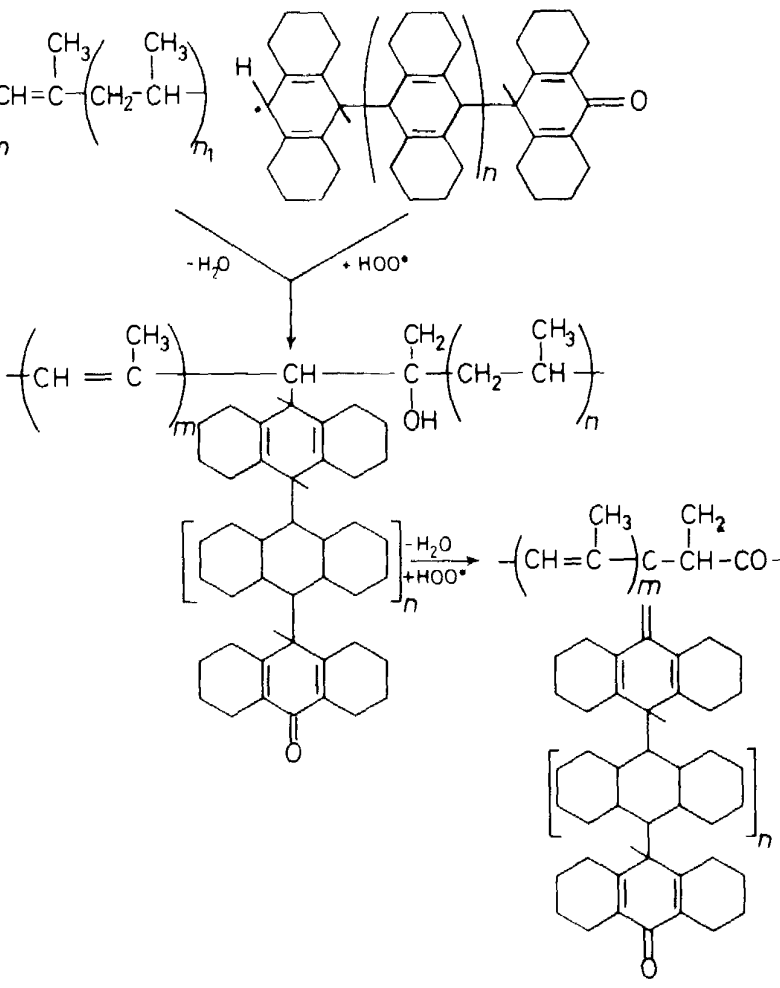
polypropylene in the presence of anthracene and anthraquinone and, apparently, is a graft copolymer of polyene with anthracene and polymer products forming in oxidizing dehydropolycondensation of anthracene containing PMC.

Significant inhibiting effects in polypropylene oxidation in the presence of anthracene are apparently connected with the interaction between the inhibitor and the oxidizing substrate when the reactions with oxygen, peroxide or alkoxy radicals take place (see Figure 23). The region of conjugation in polypropylene macromolecules already appears in the initial stage of oxidation. Anthracene molecules are taken into complexes with polyene conjugated blocks and after that their oxidizing dehydrocondensation takes place. The PSC paramagnetic fractions are accumulated and terminate the chain propagation and formation of hydroperoxides.

This process cannot be realized to the same degree in the oxidation of ceresin. The latter does not in practice contain tertiary hydrogen and so has considerably lower reactivity with respect to oxygen and peroxide radicals.

In a general form the hypothetical scheme may be represented as shown in Scheme $V$.

The investigation of the inhibiting activity of products as it appears in joint transformations of polypropylene and anthracene has shown that their activities are much higher than that of anthracene alone. It is interesting to note that these products are very effective in thermo-oxidation inhibition of both polypropylene and ceresin [Figures 24(a) and (b)] as well as other polymers.

It has been established that after an induction period of ceresin oxidation in the presence of the S-1 fraction the decrease in the absorption band inten-

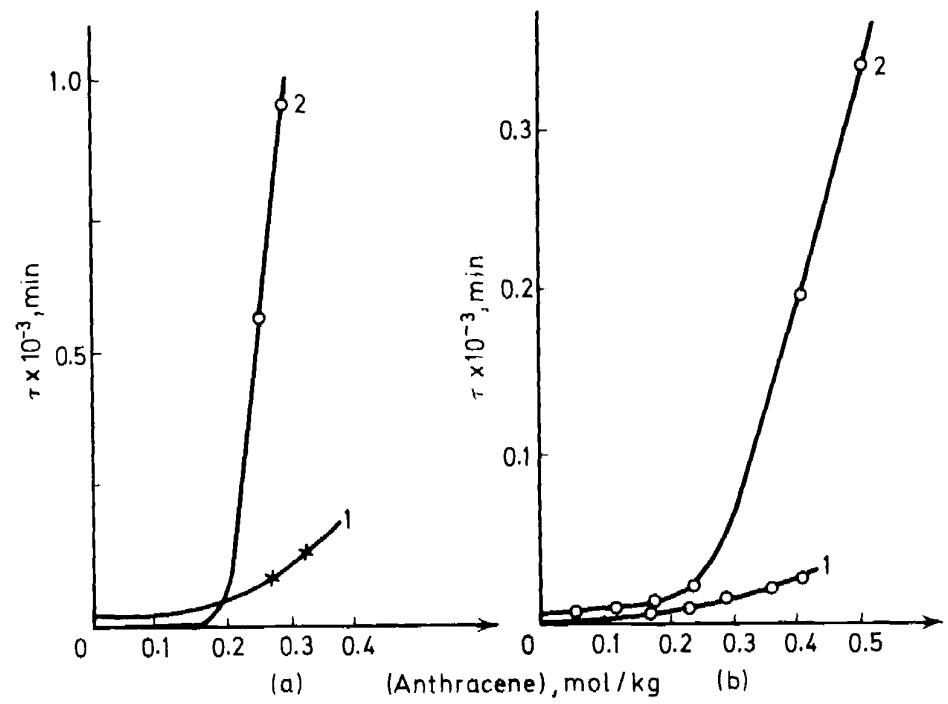

Figure 24. The inhibited thermo-oxidation of ceresin (a) and polypropylene (b) at $160^{\circ} \mathrm{C}$ in the presence of anthracene (1), polymer fraction of anthracene thermolysis (2), the fraction S-1 of the polypropylene-an thracene co-oxidation product (3) 
sity of this fraction in the visible and u.v. region and PMC concentration considerably decreases. This is connected with the expenditure of antioxidant, with the decrease in the continuous conjugated chain in it as a result of the interaction with peroxy radicals. An analogous process of PMC decay has been observed at the end of the induction period for various PCS inhibitors.

\section{CONCLUSIONS}

Based on the data considered in the present report we come to the conclusion that the theoretical predictions about the formation and the role of polyconjugated systems in thermolysis and thermo-oxidation of organic compounds are correct.

In practice, we have considered here the physical chemistry of the socalled 'collateral' reactions which determine to a considerable degree the kinetics of processes, and the structure and properties of the main substances.

The data about these processes obtained at the present time must be considered the first stage of work leading to new and more powerful ideas about the destruction and also to the methods of polymer stabilization and inhibition of analogous processes for low-molecular weight compounds.

Undoubtedly, analogous processes proceed in photolysis and radiolysis, although the kinetics and chemistry of PCS formation and the influence of PMC and polyconjugation are virtually not investigated in these cases. It must be emphasized that the knowledge of the nature and structure of forming PCS and PMC, the information about the mechanism of their transformation caused by various energies and chemical effects, and especially the ability to inactivate radicals and to regulate the amount of PMC and PCS are of great importance for the problem of stabilization.

On the other hand, the understanding of these processes opens new ways for a purposeful preparation of highly effective polymer stabilizers. Apparently, an approach based on the uses of thermolysis, thermo- and photoeffects or ionizing irradiation of low-molecular weight antioxidants in the absence or in the presence of oxygen or some other oxidizers is rather auspicious.

The expediency of this approach has been illustrated by us by using PCS-stabilizers obtained by thermolysis or thermo-oxidation of anthracene, diphenylamine, and some other analogues as the example. The transition from InH-type inhibitors, to corresponding PCS with stable PMC is rather hopeful, because in this case it is possible to solve some complex problems of thermo-oxidation inhibition at a fairly high temperature $\left(T=250^{\circ}\right.$ to $300^{\circ} \mathrm{C}$ ) and under the effect of u.v. or high energy rays.

Therefore, progress in the research on the effect of local activation and consequent intercombination transitions in the complexes of PMC or radicals stabilized by conjugation with the substances containing $\pi$-bond or heteroatoms is of particular importance.

It is also necessary because this effect may play a part in a great variety of processes with the participation of stable radicals.

One must bear in mind that the activation of transition and reactivity 
may be realized not only by the action of polyconjugated PMC but also due to such stable radicals as $\mathrm{O}_{2}, \mathrm{NO}$, etc.

These predictions may be confirmed by some examples, and in particular by the influence of oxygen and nitric oxide on the rate of CCT formation ${ }^{28}$ where for the first time the catalytic role of oxygen in thermodestruction of aromatic polyamides has been shown by means of ${ }^{18} \mathrm{O}$ (ref. 26).

All this gives basis for the conclusion that progress in work on the effect of local activation allows us to see many chemical problems including the transformation of low-molecular and polymer substances due to energy effects and oxidation.

\section{REFERENCES}

1 A. Wall, Soc. Plast. Engrs J. No. 8, 811 (1960).

2 A. A. Berlin, J. Macromol. Sci.-Chem. A5, 1187 (1971); Vysokomol. Soedin. A13, 2429 (1971).

3 A. A. Berlin, Izvest. Akad. Nauk SSSR, Ser. Khim. 59 (1965): Khim. Prom. 12, 23 (1962); Izvest. Akad. Nauk SSSR, Otdel. Khim. Nauk, 1494 (1962); Dokl. Akad. Nauk SSSR, 150, 795 (1963).

4 A. A. Berlin, 'Kinetics and mechanism of polyreactions', International Symposium on Macromolecular Chemistry, IUPAC: Budapest (1969), Plenary and Main Lectures, p 689; Vysokomol. Soedin. A13, 276 (1971).

5 A. A. Berlin, L. A. Blyumenfeld and N. N. Semenov, Izvest. Akad. Nauk SSSR, Otdel. Khim. Nauk, 1689 (1959).

6 A. A. Berlin, B. E. Davydov and B. Krentsel et al. Chemistry of Polyconjugated Systems, p 223. Khimiya: Moscow (1972).

7 B. A. Dolgoplosk, S. J. Beilin and J. N. Marevitch, Vysokomol. Soedin. A13, 1278 (1971).

8 A. A. Berlin, Chem. Technol. Polymers, No. 7-8, 134 (1960); Chem. Prom. No. 5, 375, 6, 144 (1960).

9 A. A. Berlin, Preprints IUPAC International Symposium on Macromolecular Chemistry, Prague, p 281 (1965).

10 A. A. Berlin, G. A. Vinogradov and A. A. Ovchinnikov, Internat. J. Quantum Chem. 6, 263 (1972).

11 V. A. Benderskii, L. A. Blyumenfeld and D. A. Popov, Zh. Strukt. Khim. 7, 370 (1966).

12 L. A. Blyumenfeld, V. A. Benderskii and P. A. Stundzhas, Zh. Strukt. Khim. 7, 686 (1966).

13 Kh. M. Gafurov, Thesis, Akademija Nauk Uzbekskoj SSR: Tashkent (1967).

14 I. D. Morosova and M. Je. Dyatkina, Uspekhi Khim. 37, 865 (1968).

15 A. A. Berlin, V. A. Grigorovskaya, V. P. Parini and Kh. Gafurov, Dokl. Akad. Nauk SSSR, 156, 1371 (1964).

16 A. A. Berlin, V. A. Grigorovskaya, V. K. Skachkova and V. E. Skurat, Vysokomol. Soedin. A10, 1578 (1968)

17 A. A. Berlin and N. G. Matveeva, Vysokomol. Soedin. 8, 736 (1966).

18 A. A. Berlin, M. I. Cherkashin and V. G. Zadontsev, Izvest. Akad. Nauk SSSR, Ser. Khim. 2065 (1967); Vysokomol. Soedin. B9, 91 (1960).

19 A. A. Berlin, A. P. Firsov and V. V. Yarkina, Vysokomol. Soedin. B10, 724 (1968).

20 A. A. Berlin, M. I. Cherkashin, M. V. Borshilova, G. Bantsirev and J. M. Panaiotov, Vysokomol. Soedin. A14, 9 (1972); International Conference on Chemical Transformations of Polymers, IUPAC, Vol. 2, p 38, Bratislava (1971).

21 A. A. Berlin, V. P. Parini and K. Almanbetov, Dokl. Akad. Nauk SSSR, 166, 595 (1966).

22 A. A. Berlin, R. N. Belova and A. P. Firsov, Dokl. Akad. Nauk SSSR, 180, 140 (1968); Vysokomol. Soedin. B10, 366 (1968).

23 A. A. Berlin and V. M. Kobryanskii, Izvest. Akad. Nauk SSSR, Ser. Khim. (in press).

24 A. A. Berlin, Kh. M. Gafurov, V. F. Gakhkovsky and V. P. Parini, Izvest, Akad. Nauk SSSR, Ser. Khim. 728, 746 (1966).

25 Kh. M. Gafurov, V. M. Mulikov, V. F. Gakhkovsky, V. P. Parini, A. A. Berlin and L. A. Blyumenfeld, J. Struct. Chem. 6, 649 (1945).

26 A. B. Blyumenfeld, N. Ya. Valetskaya, B. M. Kovarskaya and A. S. Akutin, Vysokomol. Soedin. B14, 403 (1972). 


\section{A. A. BERLIN}

27 A. L. Buchachenko, Thesis, Institute of Chemical Physics, Akademija Nauk SSSR : Moscow (1968).

28 S. B. Goldstein, S. D. Stavrova, J. P. Saveleva and S. S. Medvedev, Dokl. Akad. Nauk SSSR, 181, 134 (1968).

29 M. V. Bazhilova, Thesis, Institute of Chemical Physics, Akademija Nauk SSSR: Moscow (1972).

30 A. A. Berlin, G. A. Vinogradov and V. M. Bobryanskii, Izvest. Akad. Nauk SSSR, Ser. Khim. $1192(1970)$.

31 N. J. Chernorukov and S. E. Krein, Oxidation of Mineral Oils, Gostopisdat: Moscow (1946).

32 S. R. Sergienko and N. J. Cherniak, Dokl. Akad. Nauk SSSR, 113, 331 (1957)

${ }^{33}$ G. E. Zaikov, E. A. Blumberg and N. M. Emanuel, Neftekhim. 5, No. 1, 53 (1965).

34 A. V. Bobolev, E. A. Blumberg, E. G. Rozantsev and N. M. Emanuel, Dokl. Akad. Nauk SSSR, 80, 1139 (1968).

35 A. A. Berlin and G. V. Belova, Uspekhi Khimii i Fizicheskoi Khimii Polimerov, p 3. Nauka: Moscow (1970).

36 A. A. Berlin, Uspekhi Khim. (in press).

37 A. A. Berlin, A. P. Firsov and V. V. Yarkina, International Symposium on Chemical Transformations of Polymers, IUPAC, Vol. 2, p 34: Bratislava (1971).

38 V. V. Yarkina, Thesis, Moscow State University: Moscow (1968).

39 V. K. Belyakov, A. A. Berlin, V. P. Dubyana, L. V. Nevski and O. G. Tarakanov, Plastmassy, No. 8, 35 (1968); Vysokomol. Soedin. A8, 1677 (1967).

40 A. A. Berlin, V. K. Belyakov, V. A. Orlov and O. G. Tarakanov, Kinetika i Kataliz, 3, 687 (1967).

41 B. K. Belyakov, J. M. Bukin, O. G. Tarakanov and A. A. Berlin, Vysokomol. Soedin. A13, $1585(1971)$.

42 A. A. Berlin, B. E. Davydov, B. Krentsel et al. Chemistry of Polyconjugated Systems, p 72: Khimiya: Moscow (1972); Vysokomol. Soedin. (in press).

43 A. A. Berlin and S. I. Bass, Starenie i Stabilizatsya Polimerov, Khimiya: Moscow (1966).

44 A. A. Berlin, A. A. Ivanov and A. P. Firsov, Vysokomol. Soedin. B12, 80 (1970).

${ }^{45}$ L. L. Yasina, B. A. Gromov, V. B. Miller and J. A. Shlyaptsinov. Vysokomol. Soedin, 8, 1411 (1966).

46 J. J. Levantovskaya, V. V. Guryanova, B. M. Kovarskaya and J. J. Slonim, Vysokomol. Soedin. A11, 1043 (1969).

47 A. Ivanov, Thesis, Moscow State University: Moscow (1969).

48 A. A. Berlin, A. A. Ivanov, J. J. Mirotvortsev and G. K. Goryacheva, Vysokomol. Soedin. B12, 563 (1970). XIth Microsymposium on the Mechanism of Inhibition Processes in Polymers, IUPAC, Prague (1972).

49 J. Gömöry, A. Gömöryova, R. Reya and J. Stimel, Europ. Poly. J.-Suppl. 545 (1969); 6, $1047(1970)$.

50 J. Gömory, J. Stimel, R. Reya and A. Gömöryova, J. Polymer Sci. C16, 451 (1967).

51 J. Pospišil, E. Lisá and J. Buden, Europ. Polym. J. 6, 1347 (1970).

52 A. A. Berlin, A. A. Ivanov and V. J. Popovkina, Vysokomol. Soedin. A13, 2724 (1971). 